\title{
Listagem, Banco de Esporos e Guia Ilustrado de Samambaias e Licófitas da Reserva Biológica da Serra da Pedra Branca, Caldas, Minas Gerais
}

\author{
Eric Arruda Williams ${ }^{1}$, Massimo G. Bovini ${ }^{2}$ \& Claudine M. Mynssen ${ }^{2}$
}

Recebido em 17/10/2019 - Aceito em 11/05/2020

1 Escola Nacional de Botânica Tropical, Programa de Pós-Graduação Profissional, Instituto de Pesquisas Jardim Botânico do Rio de Janeiro, Rua Pacheco Leão 915, Rio de Janeiro/RJ, Brasil. CEP: 22.460-030. <ericarrudawilliams@ hotmail.com>.

2 Instituto de Pesquisas Jardim Botânico do Rio de Janeiro, Rua Pacheco Leão 915, Rio de Janeiro/RJ, Brasil. CEP: 22.460-030. <bovinimassimo@gmail.com,cmynssen@gmail.com>.

RESUMO - A Reserva Biológica da Serra da Pedra Branca está situada na borda ocidental da Serra da Mantiqueira, no município de Caldas, estado de Minas Gerais, Brasil. Este estudo realizou o levantamento de samambaias e licófitas dessa área. Através de expedições mensais durante 17 meses, os espécimes foram coletados, herborizados e posteriormente identificados. Ao todo, foram inventariadas 90 espécies, e a família Polypodiaceae foi a mais rica, com cerca de $21 \%$ do total de espécies. Há três espécies que integram a lista da flora ameaçada de extinção: Dicksonia sellowiana Hook., Cheilanthes regnelliana Mett. e Phlegmariurus regnellii (Maxon) B. Øllg. Foram elaborados um guia ilustrado de reconhecimento das espécies e uma listagem, além da coleta de esporos de 25 espécies, adicionados a um banco de esporos para futuros estudos de conservação.

Palavras-chave: Banco de esporos; conservação; espécies ameaçadas; plantas vasculares sem sementes.

\section{List, Spore Bank and Illustrated Guide to Ferns and Lycophytes of the Serra da Pedra Branca Biological Reserve, Caldas, Minas Gerais}

ABSTRACT - The Serra da Pedra Branca Biological Reserve is located on the western border of the Serra da Mantiqueira, in the municipality of Caldas, state of Minas Gerais, Brazil. This study surveyed ferns and lycophytes in this area. Through monthly expeditions, for 17 months the specimens were collected, herborized and subsequently identified. A total of 90 species were inventoried and the Polypodiaceae family was the richest with about $21 \%$ of the total species. There are three species on the endangered flora list: Dicksonia sellowiana Hook., Cheilanthes regnelliana Mett. and Phlegmariurus regnellii (Maxon) B. Øllg. An illustrated species recognition guide and a checklist were developed and, additionally, the spores of 25 species were collected added to a spore bank for future conservation studies.

Keywords: Spore bank; conservation; threatened species; seedless vascular plants.

\section{Lista, Banco de Esporas y Guía Ilustrada de Helechos y Lycophytes de la Reserva Biológica Serra da Pedra Branca, Caldas, Minas Gerais}

RESUMEN - La Reserva Biológica Serra da Pedra Branca se encuentra en el borde occidental de la Serra da Mantiqueira, en el municipio de Caldas, estado de Minas Gerais, Brasil. Este estudio encuestó helechos y licofitas en esta área. A través de expediciones mensuales durante 17 meses, los especímenes fueron recolectados, herborizados y posteriormente identificados. En total, se inventariaron 90 especies y la familia Polypodiaceae fue la más rica con aproximadamente el $21 \%$ del total de especies. Hay tres especies en la lista de flora en peligro de extinción: Dicksonia sellowiana Hook., Cheilanthes regnelliana Mett. y Phlegmariurus regnellii (Maxon) B. Øllg. Se desarrollaron una guía ilustrada de reconocimiento de especies y una lista, además, se recogieron las esporas de 25 especies en un banco de esporas para futuros estudios de conservación.

Palabras clave: Banco de esporas; conservación; especies amenazadas; plantas vasculares sin semillas. 


\section{Introdução}

Estima-se, no mundo todo, a ocorrência de 13.600 espécies de samambaias e licófitas; entretanto, a distribuição geográfica na região tropical não é homogênea, e as montanhas possuem maior diversidade quando comparadas às áreas de planície (Tryon 1985, Moran 2008). No Brasil, ocorrem mais de 1.300 espécies de samambaias e licófitas, grande parte concentrada no bioma Mata Atlântica na região sudeste, sendo Minas Gerais o estado que tem a maior riqueza, totalizando 707 espécies (Flora do Brasil 2020, em construção).

A flora de samambaias e licófitas do estado de Minas Gerais vem sendo conhecida a partir de levantamentos florísticos em remanescentes florestais realizados ao longo dos últimos anos (Melo \& Salino 2002, 2007; Figueiredo \& Salino 2005; Souza et al. 2012; Rolim 2007; Salino \& Almeida 2008; Viveros 2010; Rezende et al. 2013). Além disso, alguns grupos taxonômicos com elevada diversidade, como Polypodiaceae e Dryopteridaceae, foram inventariados nesse estado (Rolim \& Salino 2008, Salino \& Garcia 2008). Embora tenha sido realizada uma análise da distribuição geográfica das pteridófitas para o estado de Minas Gerais (Almeida 2008), ainda há lacunas que precisam ser estudadas.

O conhecimento da germinação, conservação de esporos ou desenvolvimento de gametófitos pode contribuir para a conservação ex situ. Alguns estudos incluem espécies de samambaias com caule arborescente e que são forófitos para várias outras espécies epífitas (Moreira 2005, Azevedo et al. 2008, Biasi \& Valle 2009, Marcon et al. 2014, Vargas \& Droste 2014). Entretanto, o uso de técnicas de cultivo visando à conservação ex situ de samambaias e licófitas ainda é escasso no Brasil. Assim, a criação de um banco de esporos é uma estratégia para viabilizar a adequação e aplicação de técnicas direcionadas para a conservação de espécies.

Estudos que apontam áreas com deficiência de informações e prioritárias para a conservação no estado de Minas Gerais incluem a Área de Proteção Ambiental Santuário Ecológico da Pedra Branca, no município de Caldas (Drumond et al. 2005, Almeida 2008). Ao todo, 13 espécies da flora vascular são indicadas como ameaçadas nessa área, das quais duas categorizadas "em perigo" e uma como "criticamente em perigo" (Rezende et al. 2013, Martinelli \& Moraes 2013, Brasil 2014).
O presente trabalho tem como objetivo fazer o inventário das samambaias e licófitas ocorrentes na Reserva Biológica da Serra da Pedra Branca (REBIO da Serra da Pedra Branca), localizada no município de Caldas, no estado de Minas Gerais, implementar um banco de esporos de samambaias e licófitas das espécies coletadas na área, e elaborar um guia fotográfico das espécies mais frequentes.

\section{Material e Métodos}

\section{Área de estudo}

A REBIO da Serra da Pedra Branca está localizada no município de Caldas, no estado de Minas Gerais, no sudeste do planalto de Poços de Caldas, nas coordenadas $21^{\circ} 58^{\prime} \mathrm{S}$ e $46^{\circ} 22^{\prime} \mathrm{O}$, DATUM WGS 84 (Figura 1). O planalto situa-se no limite nordeste da bacia sedimentar do Paraná, com os terrenos pré-cambrianos do complexo cristalino brasileiro, na borda ocidental da Mantiqueira, sendo caracterizado pela presença de uma caldeira vulcânica com predominância de rochas plutônicas de granulação fina e rochas do grupo das nefelia-sienitos leucocráticas subvulcânicas (Moraes \& Jiménes-Rueda 2008).

O município de Caldas apresenta uma variação de altitude entre 950 e $1840 \mathrm{~m}$. Seu relevo é formado por morros com solos espessos de diversas composições graníticas e áreas serranas constituídas por rochas sieníticas. O clima, na classificação de Köppen, é do tipo $\mathrm{Cwb}$, com temperatura anual média de $18^{\circ} \mathrm{C}$, e a pluviosidade entre 1648 e $1762 \mathrm{~mm}$ anuais (Scolforo et al. 2008, Winters 1981).

A REBIO da Serra da Pedra Branca foi criada em 5 de dezembro de 1988, Decreto do município de Caldas $n^{\circ} 326 / 88$. Está inserida na Área de Proteção Ambiental (APA) Santuário Ecológico da Pedra Branca, e possui 122,19ha de área, com um raio de $3000 \mathrm{~m}$ como zona de amortecimento, com altitude variando entre 1150 e 1840m e (Figura 1). O local apresenta as fisionomias-ecológicas floresta estacional semidecidual alto montana (Figuras 2 e 3 ), refúgios ecológicos e campos de altitude antropizados (Confort et al. 2007, IBGE 2012). Trata-se de um maciço de rochas sieníticas com pórfiros de feldspatos potássico, sendo esta a mesma formação geológica da Serra do Itatiaia (Confort et al. 2007). 


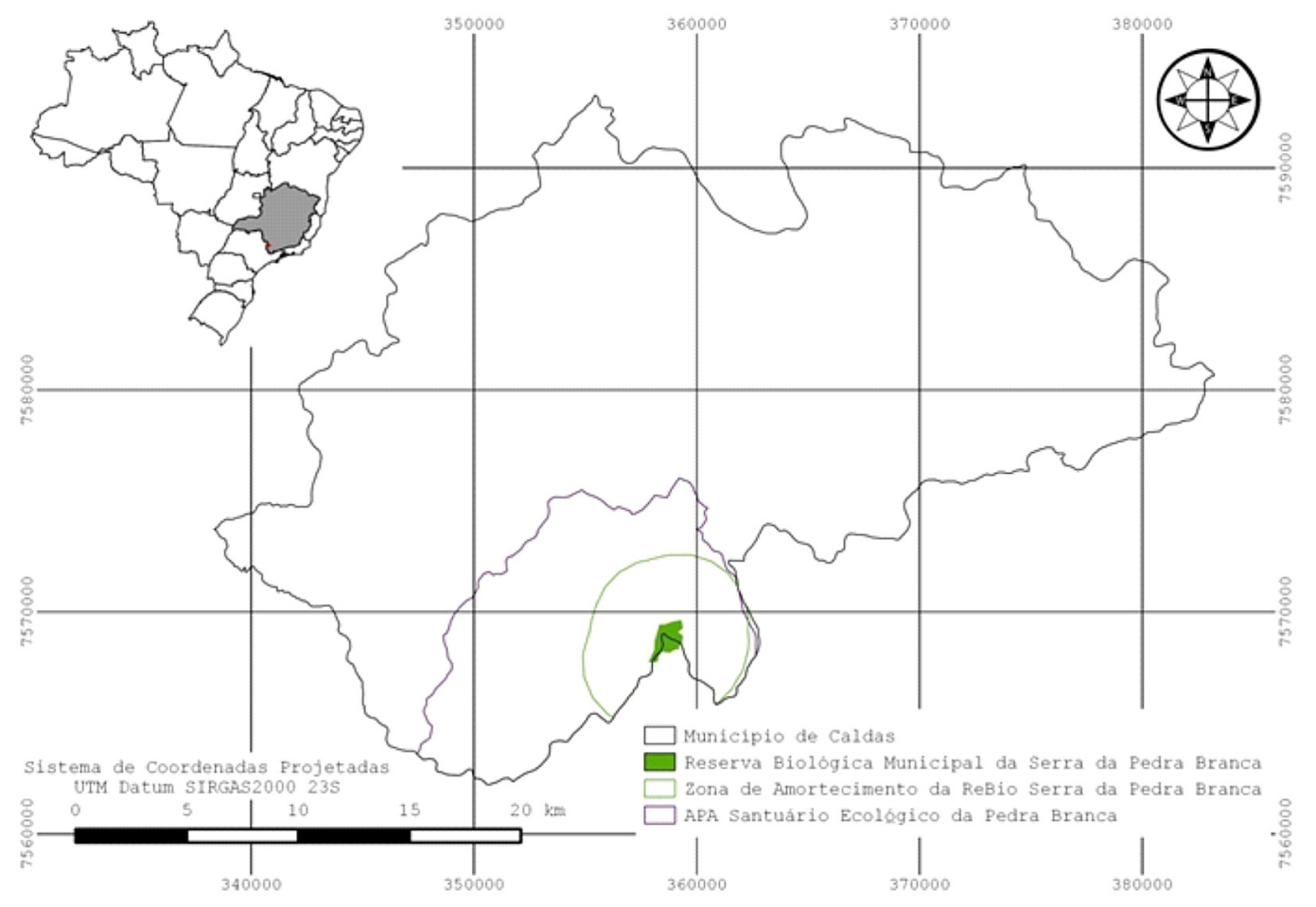

Figura 1 - Mapa indicando o estado de Minas Gerais, o município de Caldas, APA Santuário Ecológico da Pedra Branca com a zona de amortecimento (linha verde) em torno da REBIO da Serra da Pedra Branca (verde).

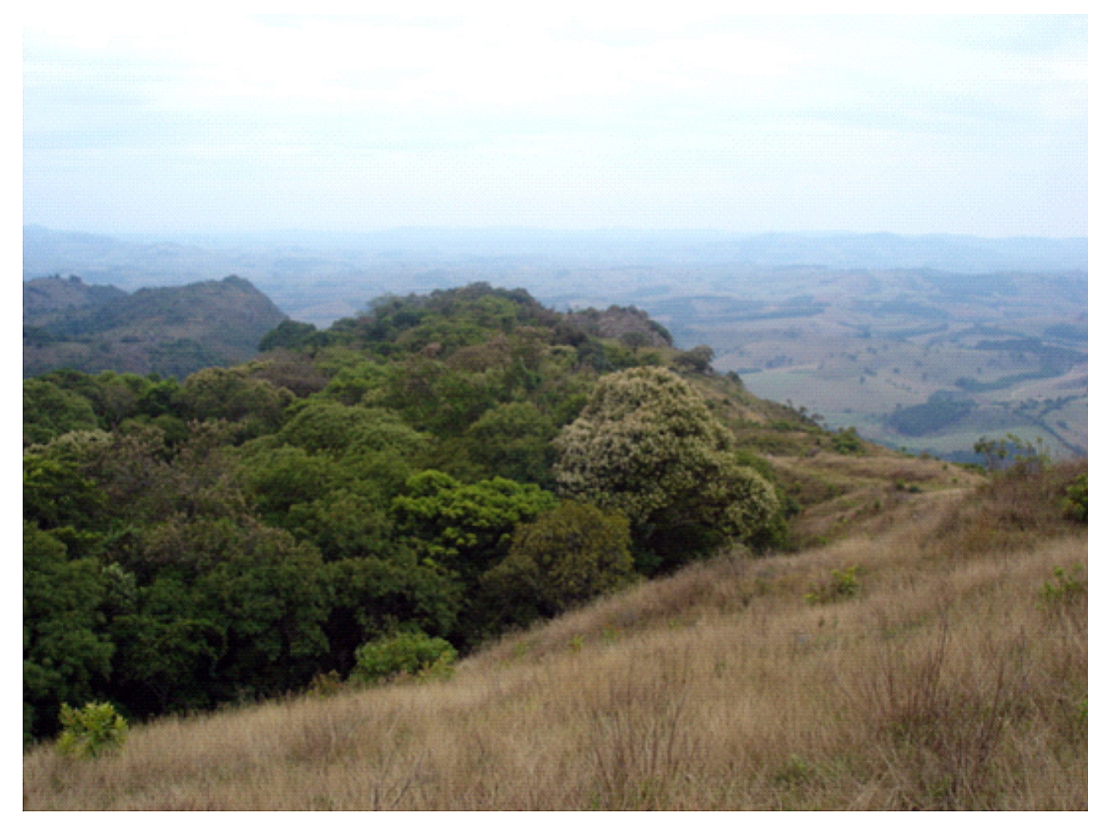

Figura 2 - Aspecto geral da REBIO da Serra da Pedra Branca mostrando um fragmento de floresta estacional semidecidual montana e campo de altitude antropizado. 


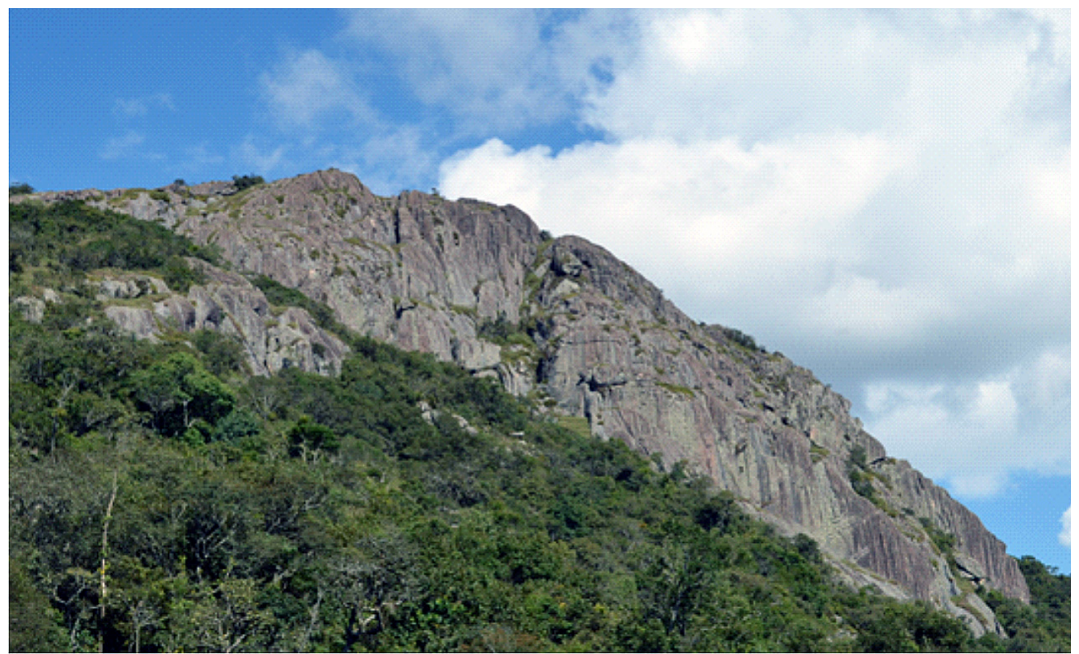

Figura 3 - Aspecto geral da REBIO da Serra da Pedra Branca mostrando o cume da Serra da Pedra Branca, com $1.840 \mathrm{~m}$.

\section{Trabalho de campo}

Foram realizadas expedições mensais totalizando 17 visitas ao local no período de 12/02/2015 a 04/07/2016. As amostras de samambaias e licófitas foram coletadas em todos os tipos de ambientes na área, como às margens das trilhas, em locais com terreno escarpado de difícil acesso pela declividade e também na área de amortecimento da REBIO da Serra da Pedra Branca. Os espécimes foram herborizados conforme o método proposto por Fidalgo \& Bononi (1989). A identificação taxonômica foi feita a partir de literatura específica para o grupo, de consulta a especialistas e comparação nos herbários da Fundação Jardim Botânico de Poços de Caldas (AFR, não indexado) e do Instituto de Pesquisas Jardim Botânico do Rio de Janeiro (RB), onde, posteriormente, foram incorporados. Seguimos a proposta de classificação de samambaias e licófitas do "Pteridophyte Phylogeny Group - PPG I” (PPG I 2016).

\section{Banco de esporos}

Amostras de folhas férteis foram coletadas, acondicionadas em envelope de papel $e$ depositadas em estufa elétrica de secagem sem circulação de ar a $25{ }^{\circ} \mathrm{C}$ por 72 horas (Moreira 2005). Cada amostra foi acondicionada em um criotubo de polipropileno cor âmbar e armazenada em refrigerador a $-5{ }^{\circ} \mathrm{C} \pm 2{ }^{\circ} \mathrm{C}$. Os tubos criogênicos foram etiquetados com o número da coleta e incorporados aos bancos de esporos do Instituto de Pesquisas Jardim Botânico do Rio de Janeiro e da Fundação Jardim Botânico de Poços de Caldas.

\section{Análise florística}

Foi elaborada uma lista com espécies identificadas $e$ indicado um voucher para cada uma (Tabela 1). Considerando que a REBIO da Serra da Pedra Branca possui fitofisionomias distintas, as espécies foram analisadas quanto ao habitat: florestal, área antropizada e afloramento rochoso. Também foram indicados os substratos preferenciais por espécie. Foi elaborado um guia de campo de acordo com o modelo proposto por Field Museum (fieldguides.fieldmuseum.org). As fotos das espécies seguem ordem alfabética de gênero, sendo priorizadas aquelas facilmente encontradas na área e também as espécies ameaçadas de extinção (Anexo 1-7).

\section{Resultados e Discussão}

Foram registradas 87 espécies de samambaias e 3 espécies de licófitas na REBIO da Serra da Pedra Branca, das quais foram selecionadas 41 espécies para compor um guia ilustrado de campo (Tabela 1 e Anexo 1-7).

Atualmente, são indicadas 707 espécies representadas em 35 famílias em Minas Gerais (Heringer et al. 2020). É considerado o estado 
brasileiro que possui o maior número de espécies samambaias e licófitas, sendo Pteridaceae $e$ Dryopteridaceae as famílias de maior riqueza, com 196 e 179 espécies, respectivamente (Prado et al. 2015). Na REBIO da Serra da Pedra Branca, Polypodiaceae foi a família com a maior representatividade, com $21 \%$ do total espécies (19), seguida de Thelypteridaceae - $12 \%$ (11), Pteridaceae e Blechnaceae - $11 \%$ cada (10 espécies cada). Um inventário realizado na Serra Negra, no complexo da Serra da Mantiqueira, reconheceu 209 táxons de samambaias e licófitas, sendo Polypodiaceae também o grupo predominante (Souza et al. 2012). Acreditamos que a predominância dessa família nessas áreas se deve às matas nebulares, onde ocorrem muitas espécies epífitas, hábito comum em Polypodiceae.

No estado de Minas Gerais, a flora vascular de várias unidades de conservação (UCs) vem sendo estudada nos últimos anos. Entretanto, a extensão da área, o esforço amostral e as diferentes fitofisionomias são desafiadores e geram resultados muito distintos. Isso pode ser percebido quando analisamos as listagens de táxons e a área total das UCs. Na APA Fernão Dias, por exemplo, que possui uma área com cerca de 180.000 ha, foram registradas 173 espécies de samambaias e licófitas (Melo \& Salino 2007). Já no Parque Estadual do Rio Doce, com cerca de 36.000ha de área, altitudes entre 200 e $500 \mathrm{~m}$, foram inventariadas 123 espécies de samambaias e licófitas (Melo \& Salino 2007, Graçano et al. 1998). Esse Parque possui uma vegetação caracterizada como floresta estacional semidecidual submontana, $e$ acreditamos que a fitofisionomia $e$ a altitude poderiam ter relação com a riqueza e distribuição das espécies nessa área, uma vez que a maior diversidade está nas áreas montanhosas, como já apontado por diversos autores (Tryon 1985, Moran 2008).

Uma avaliação sobre a eficácia das UCs para a conservação das samambaias e licófitas em Minas Gerais mostrou que mais de $10 \%$ das espécies desse estado encontram-se fora de área protegida; entretanto, as áreas de proteção ainda constituem uma ferramenta para a conservação de espécies (Heringer et al. 2020).

A análise dos habitat preferenciais indicou 69 espécies na área florestal, o que representa cerca de $77 \%$ dos táxons. A área atropizada e os afloramentos rochosos tiveram o número de táxons quase equivalentes: $11 \%$ e $12 \%$, respectivamente.
As áreas florestais sofrem constantes influências antrópicas, tais como compactação do solo $e$ supressão da vegetação de sub-bosque pelo gado, supressão da vegetação das bordas por roçados e eventuais cortes ilegais de espécies arbóreas. Como resultado, há uma alteração no sombreamento, na umidade e na qualidade do solo, modificando progressivamente a cobertura vegetal. Assim, embora tenhamos reconhecido as áreas florestais $e$ antropizadas como distintas, existe uma relação entre elas que é diretamente influenciada pela expansão da área de amortecimento da REBIO da Serra da Pedra Branca.

É no limite entre essas áreas que ocorrem as espécies Pteridium esculentum subsp. arachnoideum (Kaulf.) Thomson, que aparecem em área perturbadas e cultivadas (Schwartsburd 2017), e Dicksonia sellowiana (Dicksoniaceae), classificada como "em perigo", conforme a Lista Nacional Oficial das Espécies da Flora Brasileira (Brasil 2014). Embora seja estimada a existência de três milhões de indivíduos de Dicksonia sellowiana em ambientes naturais, suspeita-se que mais de $50 \%$ de população original tenha sido suprimida da natureza para o fornecimento de substrato utilizado no cultivo de plantas ornamentais (Martinelli \& Moraes 2013). Como uma consequência do crescimento lento dos indivíduos dessa espécie, alguns podem possuir mais de 200 anos, dificultando, assim, os projetos de restauração em curto ou médio prazo (Martinelli \& Moraes 2013). Além disso, análises qualitativas e quantitativas mostram que os indivíduos epífitos são significativamente mais abundantes no cáudice dessa espécie do que dos outros fetos arborescentes (Marques \& Krupek 2018). A área de estudo apresenta três populações da espécie, localizadas nas altitudes de $1.339 \mathrm{~m}, 1.650 \mathrm{~m} e$ $1.728 \mathrm{~m}$, totalizando menos de 10 indivíduos adultos. Os fragmentos florestais onde estão situadas são de difícil acesso; como consequência, são mais preservados da ação antrópica.

No afloramento rochoso, as 11 espécies ocorremem fendas, sob o sombreamento de rochas, entre a vegetação graminoide ou nas áreas com incidência solar direta. Duas espécies, registradas apenas nessa área, estão incluídas na lista de ameaçadas: Cheilanthes regnelliana (Pteridaceae) e Phlegmariurus regnellii (Lycopodiaceae) (Martinelli \& Moraes 2013). Cheilanthes regnelliana é indicada como "em perigo" na Lista Nacional Oficial das Espécies da Flora Brasileira 
Ameaçadas de Extinção (Brasil 2014). Trata-se de uma espécie endêmica da Serra da Mantiqueira que ocorre em afloramentos rochosos nos estados de Minas Gerais e São Paulo, restrita a ambientes fragmentados, cujo habitat é descaracterizado pelas atividades agropecuárias e de infraestrutura (Martinelli \& Moraes 2013). Phlegmariurus regnellii aparece como "criticamente em perigo" na Lista Nacional Oficial das Espécies da Flora Brasileira (Brasil 2014). Considerando a sua extensão de ocorrência $\left(272,890 \mathrm{~km}^{2}\right)$, a área de ocupação $\left(4.000 \mathrm{~m}^{2}\right)$ e a perda $90 \%$ da vegetação nativa do município, suspeita-se que ocorreu uma redução de $80 \%$ de sua população (Martinelli \& Moraes 2013). Além disso, essa espécie possui poucos registros de coleta, e ocorre exclusivamente em afloramentos rochosos em altitudes superiores a $1.200 \mathrm{~m}$, sendo considerada rara (Øllgaard 1992, Martinelli \& Moraes 2013). Na área de estudo, suas populações têm poucos indivíduos, que são impactados pelo turismo desordenado e pelas atividades minerárias, levando à sua redução (Williams et al. 2014).

A área antropizada é caracterizada como um campo de altitude com grande intervenção humana, $e$ foi a que apresentou a menor riqueza de espécies - ao todo, dez. Além de ser uma área que possui incidência solar direta, é muito utilizada para pecuária, o que afeta a ocorrência das espécies.
Em relação ao substrato, verificamos que a maioria das espécies é terrestre (65), o que é corroborado por outros levantamentos florísticos (e.g. Forsthofer \& Athayde Filho 2012, Gonzatti et al. 2014). As espécies epífitas totalizaram 15 e, com exceção de uma Microgramma squamulosa (Kaulf.) de la Sota, que ocorreu sobre forótito no afloramento rochoso, todas as demais são da área florestal, que constitui uma mata nebular. As dez espécies rupícolas ocorrem exclusivamente nesse habitat (Tabela 1).

Os esporos de 25 espécies foram incorporados ao banco de esporos do Jardim Botânico de Poços de Caldas e do Jardim Botânico do Rio de Janeiro (Tabela 1). Embora muitos jardins botânicos possuam um banco de sementes visando à conservação ex situ de espécies vasculares nativas, os bancos de esporos de samambaias e licófitas ainda são raros. Sabe-se que a conservação de plantas em coleções in situ e ex situ em jardins botânicos tropicais é uma estratégia importante em países megadiversos e com espécies ameaçadas de extinção (Costa et al. 2016). A análise de dados dos jardins botânicos brasileiros mostra que cerca de um terço das espécies ameaçadas de extinção está mantido em coleções vivas (Costa et al. 2016). Portanto, o armazenamento dos esporos poderá viabilizar estudos voltados à conservação.

Tabela 1 - Lista de espécies de samambaias e licófitas da REBIO da Serra da Pedra Branca. São indicados: habitat, $\mathrm{F}=$ florestal, $\mathrm{AA}=$ área antropizada, $\mathrm{AR}=$ afloramento rochoso; substrato: $\mathrm{E}=$ epífita, $\mathrm{T}=$ terrestre, $\mathrm{R}=$ rupícola; $\mathrm{X}=$ espécies incluídas no banco de esporos.

\begin{tabular}{|c|c|c|c|c|}
\hline Táxons & Habitat & Substrato & $\begin{array}{l}\text { Banco de } \\
\text { esporos }\end{array}$ & Voucher \\
\hline \multicolumn{5}{|c|}{ Licófitas } \\
\hline \multicolumn{5}{|l|}{ Lycopodiaceae } \\
\hline Lycopodium clavatum $\mathrm{L}$. & AA & $\mathrm{T}$ & & Williams 574 \\
\hline Phlegmariurus regnellii (Maxon) B. Øllg. & AR & $\mathrm{R}$ & & Williams 469 \\
\hline \multicolumn{5}{|l|}{ Selaginellaceae } \\
\hline Selaginella macrostachya (Spring) Spring & AR & $\mathrm{R}$ & & Williams 387 \\
\hline \multicolumn{5}{|c|}{ Samambaias } \\
\hline \multicolumn{5}{|l|}{ Anemiaceae } \\
\hline Anemia mandioccana Raddi & $\mathrm{F}$ & $\mathrm{T}$ & & Williams 101 \\
\hline Anemia phyllitidis (L.) Sw. & $\mathrm{F}$ & $\mathrm{T}$ & $\mathrm{X}$ & Williams 483 \\
\hline Anemia villosa Humb. \& Bonpl. ex Willd. & $\mathrm{F}$ & $\mathrm{T}$ & & Williams 276 \\
\hline
\end{tabular}


Tabela 1 - Lista de espécies de samambaias e licófitas da REBIO da Serra da Pedra Branca. São indicados: habitat, $\mathrm{F}=$ florestal, $\mathrm{AA}=$ área antropizada, $\mathrm{AR}=$ afloramento rochoso; substrato: $\mathrm{E}=$ epífita, $\mathrm{T}=$ terrestre, $\mathrm{R}=$ rupícola; $\mathrm{X}=$ espécies incluídas no banco de esporos.

continuação

\begin{tabular}{|c|c|c|c|c|}
\hline Táxons & Habitat & Substrato & $\begin{array}{c}\text { Banco de } \\
\text { esporos }\end{array}$ & Voucher \\
\hline \multicolumn{5}{|c|}{ Samambaias } \\
\hline \multicolumn{5}{|l|}{ Aspleniaceae } \\
\hline Asplenium auriculatum $\mathrm{Sw}$. & $\mathrm{F}$ & $\mathrm{E}$ & & Williams 586 \\
\hline Asplenium auritum $\mathrm{Sw}$. & $\mathrm{F}$ & $\mathrm{T}$ & $\mathrm{X}$ & Williams 579 \\
\hline Asplenium claussenii Hieron. & $\mathrm{F}$ & $\mathrm{T}$ & & Williams 536 \\
\hline Asplenium feei Kunze ex Fée & $\mathrm{F}$ & E & & Williams 585 \\
\hline Asplenium incurvatum Fée & $\mathrm{F}$ & $\mathrm{T}$ & & Williams 595 \\
\hline Asplenium praemorsum $\mathrm{Sw}$. & $\mathrm{F}$ & $\mathrm{T}$ & $\mathrm{X}$ & Williams 510 \\
\hline Asplenium radicans L. var. partitum (Klotzsch) Hieron. & $\mathrm{F}$ & $\mathrm{T}$ & & Williams 548 \\
\hline Asplenium serra Langsd. \& Fisch. & $\mathrm{AR}$ & $\mathrm{R}$ & $\mathrm{X}$ & Williams 508 \\
\hline \multicolumn{5}{|l|}{ Athyriaceae } \\
\hline Deparia petersenii (Kunze) M. Kato & $\mathrm{F}$ & $\mathrm{T}$ & $\mathrm{X}$ & Williams 428 \\
\hline Diplazium asplenioides (Kunze) C.Presl & $\mathrm{F}$ & $\mathrm{T}$ & & Williams 569 \\
\hline Diplazium lindbergii (Mett.) Christ & $\mathrm{F}$ & $\mathrm{T}$ & & Williams 148 \\
\hline \multicolumn{5}{|l|}{ Blechnaceae } \\
\hline Austroblechnum divergens (Kunze) Gasper \& V.A.O. Dittrich & $\mathrm{F}$ & $\mathrm{T}$ & & Williams 165 \\
\hline Blechnum asplenioides $\mathrm{Sw}$. & AA & $\mathrm{T}$ & & Williams 571 \\
\hline Blechnum austrobrasilianum de la Sota & $\mathrm{F}$ & $\mathrm{T}$ & & Williams 497 \\
\hline Blechnum gracile Kaulf. & $\mathrm{F}$ & $\mathrm{T}$ & & Williams 565 \\
\hline Blechnum occidentale L. & $\mathrm{F}$ & $\mathrm{T}$ & $\mathrm{x}$ & Williams 572 \\
\hline Blechnum polypodioides Raddi & AA & $\mathrm{T}$ & & Williams 570 \\
\hline Lomaridium plumieri (Kunze) Gasper \& V.A.O. Dittrich & $\mathrm{F}$ & $\mathrm{T}$ & & Williams 161 \\
\hline Neoblechnum brasiliense (Desv.) Gasper \& V.A.O. Dittrich & $\mathrm{F}$ & $\mathrm{T}$ & & Williams 365 \\
\hline Parablechnum cordatum (Desv.) Gasper \& Salino & $\mathrm{F}$ & $\mathrm{T}$ & & Williams 249 \\
\hline Parablechnum proliferum (Rosenst.) Gasper \& Salino & AA & $\mathrm{T}$ & & Williams 160 \\
\hline \multicolumn{5}{|l|}{ Cyatheaceae } \\
\hline Alsophila sternbergii (Sternb.) D.S.Conant & $\mathrm{F}$ & $\mathrm{T}$ & $\mathrm{X}$ & Williams 543 \\
\hline Cyathea atrovirens (Langsd. \& Fisch.) Domin & $\mathrm{F}$ & $\mathrm{T}$ & & Williams 172 \\
\hline Cyathea delgadii Sternb. & $\mathrm{F}$ & $\mathrm{T}$ & & Williams 131 \\
\hline Sphaeropteris gardneri (Hook.) R.M. Tryon & AA & $\mathrm{T}$ & & Williams 500 \\
\hline \multicolumn{5}{|l|}{ Dennstaedtiaceae } \\
\hline Dennstaedtia cicutaria (Sw.) T. Moore & $\mathrm{F}$ & $\mathrm{T}$ & $\mathrm{x}$ & Williams 526 \\
\hline Dennstaedtia cornuta (Kaulf.) Mett. Moore & $\mathrm{F}$ & $\mathrm{T}$ & & Williams 137 \\
\hline Pteridium esculentum subsp. arachnoideum (Kaulf.) Thomson & AA & $\mathrm{T}$ & & Williams 511 \\
\hline \multicolumn{5}{|l|}{ Dicksoniaceae } \\
\hline Dicksonia sellowiana Hook. & $\mathrm{F}$ & $\mathrm{T}$ & $\mathrm{X}$ & Williams 463 \\
\hline
\end{tabular}


Tabela 1 - Lista de espécies de samambaias e licófitas da REBIO da Serra da Pedra Branca. São indicados: habitat, $\mathrm{F}=$ florestal, $\mathrm{AA}=$ área antropizada, $\mathrm{AR}=$ afloramento rochoso; substrato: $\mathrm{E}=$ epífita, $\mathrm{T}=$ terrestre, $\mathrm{R}=$ rupícola; $\mathrm{X}=$ espécies incluídas no banco de esporos.

continuação

\begin{tabular}{|c|c|c|c|c|}
\hline Táxons & Habitat & Substrato & $\begin{array}{l}\text { Banco de } \\
\text { esporos }\end{array}$ & Voucher \\
\hline \multicolumn{5}{|c|}{ Samambaias } \\
\hline \multicolumn{5}{|l|}{ Didymochlaenaceae } \\
\hline Didymochlaena truncatula (Sw.) J.Sm. & $\mathrm{F}$ & $\mathrm{T}$ & & Williams 194 \\
\hline \multicolumn{5}{|l|}{ Dryopteridaceae } \\
\hline Elaphoglossum acrocarpum (Mart.) T. Moore & $\mathrm{F}$ & $\mathrm{T}$ & $\mathrm{x}$ & Williams 439 \\
\hline Elaphoglossum burchellii (Baker) C. Chr. & $\mathrm{F}$ & $\mathrm{T}$ & $\mathrm{X}$ & Williams 156 \\
\hline Elaphoglossum gayanum (Fée) T. Morre & $\mathrm{F}$ & E & $\mathrm{X}$ & Williams 234 \\
\hline Elaphoglossum hybridum (Bory) Brack. & $\mathrm{F}$ & $\mathrm{T}$ & $\mathrm{x}$ & Williams 292 \\
\hline Elaphoglossum hymenodiastrum (Fée) Brade & $\mathrm{F}$ & $\mathrm{T}$ & $\mathrm{x}$ & Williams 427 \\
\hline Elaphoglossum iguapense Brade & $\mathrm{F}$ & $\mathrm{T}$ & $\mathrm{x}$ & Williams 254 \\
\hline Elaphoglossum itatiayense Rosenst. & $\mathrm{F}$ & $\mathrm{T}$ & $\mathrm{x}$ & Williams 604 \\
\hline Elaphoglossum tectum (Humb. \& Bonpl. ex Willd.) T. Moore & $\mathrm{F}$ & $\mathrm{T}$ & & Williams 286 \\
\hline Polystichum platyphyllum (Willd.) C.Presl & $\mathrm{F}$ & $\mathrm{T}$ & & Williams 568 \\
\hline \multicolumn{5}{|l|}{ Hymenophyllaceae } \\
\hline Hymenophyllum polyanthos (Sw.) Sw. & $\mathrm{F}$ & E & & Williams 466 \\
\hline \multicolumn{5}{|l|}{ Lindsaeaceae } \\
\hline Lindsaea lancea (L.) Bedd. & $\mathrm{F}$ & $\mathrm{T}$ & & Williams 432 \\
\hline \multicolumn{5}{|l|}{ Ophioglossaceae } \\
\hline Botrypus virginianus (L.) Michx. & $\mathrm{F}$ & $\mathrm{T}$ & & Williams 485 \\
\hline \multicolumn{5}{|l|}{ Osmundaceae } \\
\hline Osmunda spectabilis Willd. & $\mathrm{F}$ & $\mathrm{T}$ & & Williams 297 \\
\hline Osmundastrum cinnamomeum (L.) C. Presl & $\mathrm{F}$ & $\mathrm{T}$ & & Williams 314 \\
\hline \multicolumn{5}{|l|}{ Polypodiaceae } \\
\hline Campyloneurum acrocarpon Fée & $\mathrm{F}$ & E & & Williams 423 \\
\hline Campyloneurum austrobrasilianum (Alston) de la Sota & $\mathrm{F}$ & E & & Williams 523 \\
\hline Campyloneurum nitidum (Kaulf.) C. Presl & $\mathrm{F}$ & E & & Williams 332 \\
\hline Lellingeria apiculata (Kunze ex Klotzsch) A.R. Sm. \& R.C. Moran & AR & $\mathrm{R}$ & & Williams 467 \\
\hline Melpomene sp. & AR & $\mathrm{R}$ & & Williams 465 \\
\hline Microgramma squamulosa (Kaulf.) de la Sota & AR & E & & Williams 475 \\
\hline Niphidium crassifolium (L.) Lellinger & & & & Williams 433 \\
\hline Pecluma camptophyllaria (Fée) M. G. Price & $\mathrm{F}$ & E & & Williams 397 \\
\hline Pecluma pectinatiformis (Lindm.) M.G.Price & $\mathrm{F}$ & E & & Williams 477 \\
\hline Pecluma recurvata (Kaulf.) M. G. Price & AR & $\mathrm{R}$ & & Williams 342 \\
\hline Pecluma robusta (Fée) M.Kessler \& A.R.Sm. & $\mathrm{F}$ & $\mathrm{T}$ & & Williams 452 \\
\hline Phlebodium pseudoaureum (Cav.) Lellinger & $\mathrm{F}$ & $\mathrm{T}$ & & Williams 478 \\
\hline Pleopeltis hisurtissima (Raddi) de la Sota & $\mathrm{F}$ & E & & Williams 540 \\
\hline
\end{tabular}


Tabela 1 - Lista de espécies de samambaias e licófitas da REBIO da Serra da Pedra Branca. São indicados: habitat, $\mathrm{F}=$ florestal, $\mathrm{AA}=$ área antropizada, $\mathrm{AR}=$ afloramento rochoso; substrato: $\mathrm{E}=$ epífita, $\mathrm{T}=$ terrestre, $\mathrm{R}=$ rupícola; $\mathrm{X}=$ espécies incluídas no banco de esporos.

continuação

\begin{tabular}{|c|c|c|c|c|}
\hline Táxons & Habitat & Substrato & $\begin{array}{c}\text { Banco de } \\
\text { esporos }\end{array}$ & Voucher \\
\hline \multicolumn{5}{|c|}{ Samambaias } \\
\hline Pleopeltis macrocarpa (Bory ex Willd.) Kaulf. & $\mathrm{F}$ & $\mathrm{E}$ & & Williams 480 \\
\hline Pleopeltis pleopeltidis (Fée) de la Sota & $\mathrm{F}$ & $\mathrm{E}$ & & Williams 299 \\
\hline Pleopeltis pleopeltifolia (Raddi) Alston & $\mathrm{F}$ & $\mathrm{E}$ & & Williams 460 \\
\hline Serpocaulon catharinae (Langsd. \& Fisch.) A. R. Sm. & AA & $\mathrm{T}$ & & Williams 256 \\
\hline Serpocaulon fraxinifolium (Jacq.) A. R. Sm. & $\mathrm{F}$ & $\mathrm{T}$ & & Williams 429 \\
\hline Serpocaulon vacillans (Link) A. R. Sm. & $\mathrm{F}$ & $\mathrm{T}$ & & Williams 241 \\
\hline \multicolumn{5}{|l|}{ Pteridaceae } \\
\hline Adiantopsis chlorophylla (Sw.) Fée & AA & $\mathrm{T}$ & & Williams 233 \\
\hline Adiantopsis radiata (L.) Fée & $\mathrm{F}$ & $\mathrm{T}$ & & Williams 199 \\
\hline Adiantum raddianum $\mathrm{C}$. Presl & AA & $\mathrm{T}$ & & Williams 557 \\
\hline Cheilanthes regnelliana Mett. & AR & $\mathrm{R}$ & $\mathrm{X}$ & Williams 581 \\
\hline Doryopteris concolor (Langsd. \& Fisch.) Kuhn & AR & $\mathrm{R}$ & & Williams 239 \\
\hline Doryopteris patula Fée & $\mathrm{F}$ & $\mathrm{T}$ & $\mathrm{X}$ & Williams 486 \\
\hline Lytoneuron crenulans (Fée) J. C. Yesilyurt & AR & $\mathrm{R}$ & & Williams 243 \\
\hline Lytoneuron ornithopus (Hook. \& Baker) Yesilyurt & AR & $\mathrm{R}$ & & Williams 447 \\
\hline Pityrogramma calomelanos (L.) Link & AA & $\mathrm{T}$ & $\mathrm{X}$ & Williams 248 \\
\hline Pteris deflexa Link & $\mathrm{F}$ & $\mathrm{T}$ & & Williams 366 \\
\hline \multicolumn{5}{|l|}{ Thelypteridaceae } \\
\hline Amauropelta eriosorus (Fée) Salino \& T. E. Almeida & $\mathrm{F}$ & $\mathrm{T}$ & & Williams 283 \\
\hline Amauropelta opposita (Vahl) Pic. Serm. & $\mathrm{F}$ & $\mathrm{T}$ & $\mathrm{X}$ & Williams 139 \\
\hline Amauropelta regnelliana (C. Chr.) Salino \& T. E. Almeida & $\mathrm{F}$ & $\mathrm{T}$ & & Williams 367 \\
\hline Amauropelta retusa (Sw.) Pic. Serm. & $\mathrm{F}$ & $\mathrm{T}$ & $\mathrm{X}$ & Williams 330 \\
\hline Amauropelta rivularioides (Fée) Salino \& Almeida & $\mathrm{F}$ & $\mathrm{T}$ & & Williams 255 \\
\hline Christella conspersa (Schrad.) Á. Löve \& D. Löve & $\mathrm{F}$ & $\mathrm{T}$ & $\mathrm{X}$ & Williams 310 \\
\hline Christella dentata (Forssk.) Brownsey \& Jermy & $\mathrm{F}$ & $\mathrm{T}$ & $\mathrm{X}$ & Williams 170 \\
\hline Chistella grandis (A.R. Sm.) A.R. Sm. & $\mathrm{F}$ & $\mathrm{T}$ & $\mathrm{X}$ & Williams 193 \\
\hline Christella hispidula (Decne) Holltum & $\mathrm{F}$ & $\mathrm{T}$ & $\mathrm{X}$ & Williams 288 \\
\hline Christella patens (Sw.) Pic. Serm. & $\mathrm{F}$ & $\mathrm{T}$ & & Williams 303 \\
\hline Goniopteris scabra (C. Presl) Brade & $\mathrm{F}$ & $\mathrm{T}$ & $\mathrm{X}$ & Williams 189 \\
\hline
\end{tabular}

\section{Agradecimentos}

À Fundação Jardim Botânico de Poços de Caldas, pela infraestrutura disponibilizada para o desenvolvimento do projeto de pesquisa. Aos curadores dos herbários do Jardim Botânico de Poços de Caldas e do Jardim Botânico do Rio de Janeiro. Aos revisores anônimos e editores desta revista. Ao amigo João Paulo de Lima Braga, pelo companheirismo durante a execução deste 
projeto de pesquisa. Ao fotógrafo Ederson José de Godoy, pelo auxílio no trabalho. Ao designer gráfico e gestor ambiental Elídio Monteiro Junior, pela elaboração do guia de campo.

\section{Referências Bibliográficas}

Almeida TE. 2008. Análise quantitativa da distribuição geográfica das espécies de pteridófitas ocorrentes no estado de Minas Gerais, Brasil. Dissertação (Mestrado em Biologia Vegetal). Instituto de Ciências Biológicas, Universidade Federal de Minas Gerais, Belo Horizonte. 64p.

Azevedo F, Droste A, Windisch PG. Aspectos da germinação de esporos e desenvolvimento da fase gametofítica de Alsophila setosa Kaulf. e Cyathea atrovirens (Langsd. \& Fisch.) Domin (Cyatheaceae). Pesquisas, Botânica. Instituto Anchietano de Pesquisas, 59: 223-236, 2008.

Biasi LA, Valle FC. Germinação de esporos de Dicksonia sellowiana e crescimento inicial sob diferentes níveis de sombreamento. Scientia Agraria, 10(2): 119-125, 2009.

Brasil. Ministério do Meio Ambiente. 2014. Portaria ${ }^{\circ}$ 443, de 17 de dezembro de 2014: Lista Nacional Oficial das Espécies da Flora Brasileira Ameaçadas de Extinção. Diário Oficial da União. <http://www.icmbio.gov. br/cepsul/images/stories/legislacao/Portaria/2014/p_ mma_443_2014_lista_esp\%C3\%A9cies_

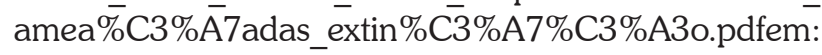
24/11/2014 >. Acesso em: 23/04/2015.

Conforti TB et al. 2007. Zoneamento Ambiental da APA "Santuário Ecológico da Pedra Branca", unidade de conservação municipal, Caldas, MG. Relatório técnico apresentado ao CODEMA de Caldas, MG.

Costa MLMN, Jackson PW, Fernandes RA, Peixoto AL. Conservation of threatened plant species in Botanic Garden Reserves in Brazil. Oryx, 52(1): 108-11, 2016.

Drumond GM, Martins CM, Machado ABM, Sebaio FA, Antonini Y. 2005. Biodiversidade em Minas Gerais: um atlas para sua conservação. Fundação Biodiversitas. 222p.

Fidalgo O, Bononi VLR. 1989. Técnicas de coleta, preservação e herborização de material botânico. Série Documentos, Instituto de Botânica. 62p.

Figueiredo JB, Salino A. Pteridófitas de quatro Reservas Particulares do Patrimônio Natural ao Sul da Região Metropolitana de Belo Horizonte, Minas Gerais, Brasil. Lundiana, 6(2): 83-94, 2005.

Samambaias e Licófitas in Flora do Brasil 2020 em construção. Jardim Botânico do Rio de
Janeiro. <http://www.floradobrasil.jbrj.gov.br/reflora/ floradobrasil/FB128483 > . Acesso em: 04/05/2020.

Forsthofer M, Athayde Filho FP. Florística e aspectos ecológicos de samambaias e licófitas ao longo do córrego Cachoeirinha, Nova Xavantina-MT. Pesquisas, Botânica, 63: 149-164, 2012.

Gonzatti F, Valduga E, Wasum ER, Scur L. Florística $e$ aspectos ecológicos de samambaias e licó tas em remanescentes de matas estacionais deciduais da serra gaúcha, Rio Grande do Sul, Brasil. Revista Brasileira de Biociências, 12(2): 90-97, 2014.

Graçano D, Prado J, Azevedo AA. Levantamento Preliminar da Pteridophyta do Parque Estadual do Rio (MG). Acta Botanica Brasilica, 12(2): 165-181, 1998.

Heringer G, Almeida TE, Dittrich VAO, Salino A. Assessing the effectiveness of protected areas for the conservation of ferns and lycophytes in the Brazilian state of Minas Gerais. Journal for Nature Conservation, 53: 125775, 2020.

IBGE - Instituto Brasileiro de Geografia e Estatística. 2012. Manual técnico da vegetação brasileira: sistema fitogeográfico, inventário das formações florestais e campestres, ... IBGE- Diretoria de Geociências. <ftp:// geoftp.ibge.gov.br/documentos/recursos_naturais/ manuais_tecnicos/manual_tecnico_vegetacao_ brasileira.p $\overline{p d f}>$. Acesso em: 01/09/2014.

Marcon C, Silveira T, Droste A. Germination and gametophyte development of Cyathea corcovadensis (Raddi) Domin (Cyatheaceae) from spores stored at low temperatures. Acta Scientiarum, Biological Sciences, 36(4): 403-410, 2014.

Marques MM, Krupek RA. Samambaias epífitas sobre cáudices de Dicksonia sellowiana Hook. (Dicksoniaceae) e Cyathea phalerata Mart. (Cyatheaceae) em remanescente de floresta ombrófila mista no município de Porto União, SC, sul do Brasil. Ambiência, 14(3): 549-560, 2018.

Martinelli G, Moraes MA. 2013. Livro Vermelho da Flora do Brasil. Centro Nacional de Conservação da Flora. $1^{\circ}$ ed. Instituto de Pesquisas Jardim Botânico do Rio de Janeiro 1100p.

Melo LCN, Salino A. Pteridófitas de duas áreas de floresta da Bacia do Rio Doce no Estado de Minas Gerais, Brasil. Lundiana, 3(2): 129-139, 2002.

Melo LCN, Salino A. Pteridófitas em fragmentos florestais da APA Fernão Dias, Minas Gerais, Brasil. Rodriguésia, 58(1): 207-220, 2007.

Moraes FT, Jiménez-Rueda JR. Fisiografia da região do Planalto de Poços de Caldas, MG/SP. Revista Brasileira de Geociências, 38(1): 196-208, 2008.

Moran RC. 2008. Diversity, biogeography and floristics, p. 367-394. In: Ranker TA \& Haufler CH (eds.). Biology 
and Evolution of Ferns and Lycophytes. Cambridge Press. 435p.

Moreira PAB. 2005. Efeito da criopreservação de esporos em nitrogênio líquido no desenvolvimento de gametófitos de Dicksonia sellowiana Hook. Dissertação (Mestrado em Biologia Vegetal). Centro de Ciências Biológicas, Universidade Federal de Santa Catarina. 64p.

Øllgaard B. Neotropical Lycopodiaceae - an overview. Annals of the Missouri Botanical Garden, (79): 687-717, 1992.

PPG I. A community-derived classification for extant lycophytes and ferns. Journal of Systematics and Evolution, 54: 563-603, 2016.

Prado J et al. Diversity of ferns and lycophytes in Brazil. Rodriguésia, 66: 1073-1083, 2015.

Rezende MG, Elias RCL, Salimena FRG, Menini Neto L. 2013. Vascular flora of Serra da Pedra Branca, Caldas, Minas Gerais and floristic relationships with altitude areas of Southeastern Region of Brazil. Biota Neotropica, 13(4).

Rolim LB. 2007. Pteridófitas do Parque Estadual do Itacolomi, Minas Gerais, Brasil. Dissertação (Mestrado em Biologia Vegetal). Instituto de Ciências Biológicas, Universidade de Brasília. 271p.

Rolim LB. \& Salino A. Polypodiaceae Bercht \& Presl (Polypodiopsida) no Parque Estadual do Itacolomi, MG, Brasil. Lundiana, 9: 83-106, 2008.

Salino A, Almeida TE. Diversidade e conservação das pteridófitas na Cadeia do Espinhaço, Brasil. Megadiversidade, 4: 196-216, 2008.
Salino A, Garcia PA. Dryopteridaceae (Polypodiopsida) no Estado de Minas Gerais, Brasil. Lundiana, 9: 3-27, 2008.

Schwartsburd PB. Flora of Espírito Santo: Dennstaedtiaceae. Rodriguésia, 68(5): 1559-1575, 2017.

Scolforo JRS, Oliveira AD, Carvalho LMT. 2008. Zoneamento ecológico-econômico do estado de Minas Gerais - componentes geofísicos e bióticos. Editora UFLA. 161p.

Souza FS, Salino A, Viana PL, Salimena FRG. Pteridófitas da Serra Negra, Minas Gerais, Brasil. Acta Botanica Brasilica, 26(2): 378-390, 2012.

Tryon RM. Fern speciation and biogeography. In: Dyer AF \& Page $\mathrm{CN}$ (Ed.). Proceedings of the Symposium held at Edinburgh, Sept. 12-16 Proceedings of the Royal Society of Edinburgh, 86 (B): 353-360, 1985.

Vargas IB, Droste A. In vitro propagation of Cyathea atrovirens (Cyatheaceae): spore storage and sterilization conditions. Revista de Biologia Tropical, 62(1): 299-308, 2014.

Viveros RS. 2010. Pteridófitas da Serra do Caraça, Minas Gerais, Brasil. Dissertação (Mestrado em Biologia Vegetal). Instituto de Ciências Biológicas da Universidade Federal de Minas Gerais. 253p.

Williams EA, Godoy E, Andrade EA. Estado de conservação da espécie Phlegmariurus regnellii (Maxon) B.Øllg. (Lycopodiaceae) na Reserva Biológica da Serra da Pedra Branca, Caldas, Minas Gerais, Brasil. Revista Regnellea Scientia, 2(1): 1-30, 2014.

Winters AAM. A geologia do maciço sienítico da Pedra Branca, Caldas, Minas Gerais. Dissertação (Mestrado em Biologia Vegetal). Universidade de São Paulo. 94p.

Biodiversidade Brasileira - BioBrasil.

Edição temática: Diálogos entre a Academia e a Gestão de Áreas Protegidas:

Programa de Pós-Graduação Profissional - Biodiversidade em Unidades de Conservação

n. 2,2020

http://www.icmbio.gov.br/revistaeletronica/index.php/BioBR

Biodiversidade Brasileira é uma publicação eletrônica científica do Instituto Chico Mendes de

Conservação da Biodiversidade (ICMBio) que tem como objetivo fomentar a discussão e a disseminação de experiências em conservação e manejo, com foco em unidades de conservação $e$ espécies ameaçadas. 
Anexo

Guia Ilustrado de Espécies 


\section{Serra da Pedra Branca, Caldas, Minas Gerais, Brasil Samambaias e Licófitas da Serra da Pedra Branca}

Eric Arruda Williams', Massimo Giussepe Bovini ${ }^{2}$ \& Claudine Massi Mynssen

'Fundação Jardim Botânico de Poços de Caldas, MG, ${ }^{2,3}$ Instituto de Pesquisas Jardim Botânico do Rio de Janeiro, RJ. Fotos: Eric Arruda Williams \& Ederson José de Godoy - Editoração Eletrônica: Elidio Monteiro Junior.

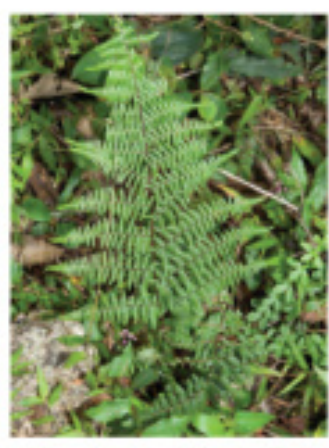

Adiantopsis chlorophylla

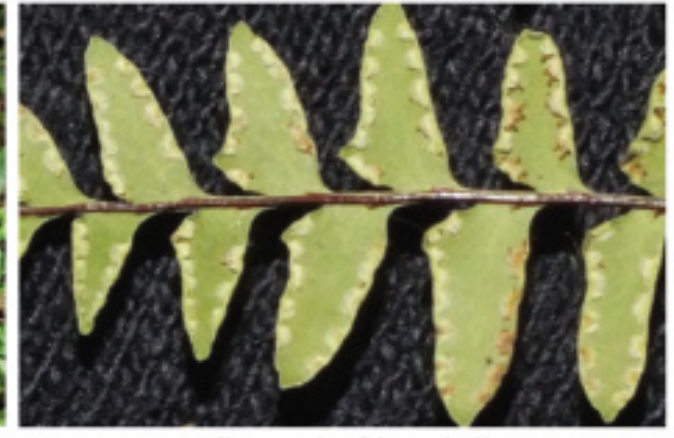

Adiantopsis chlorophylla

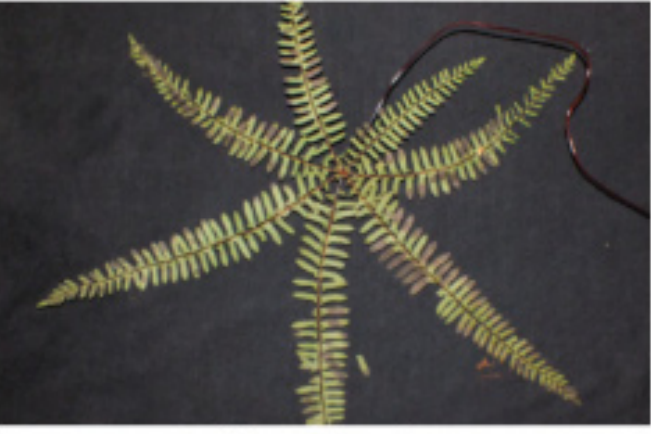

Adiantopsis radiata

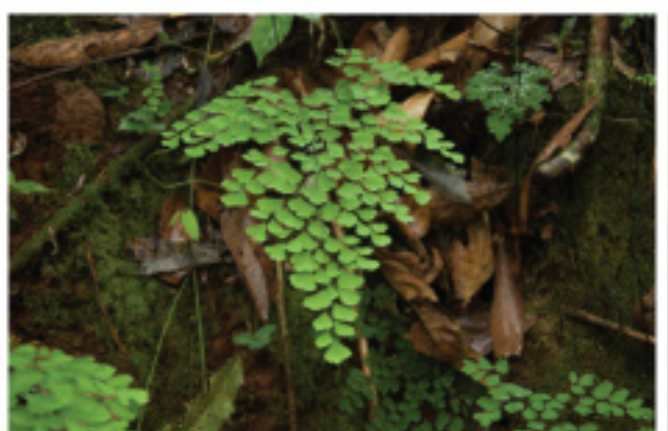

Adiatum raddianum

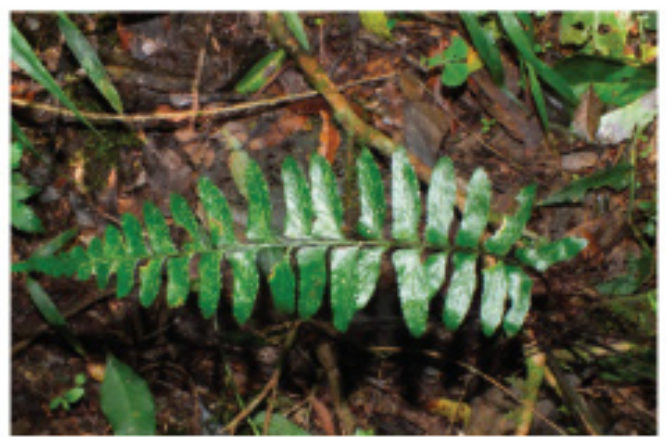

Asplenium auriculatum

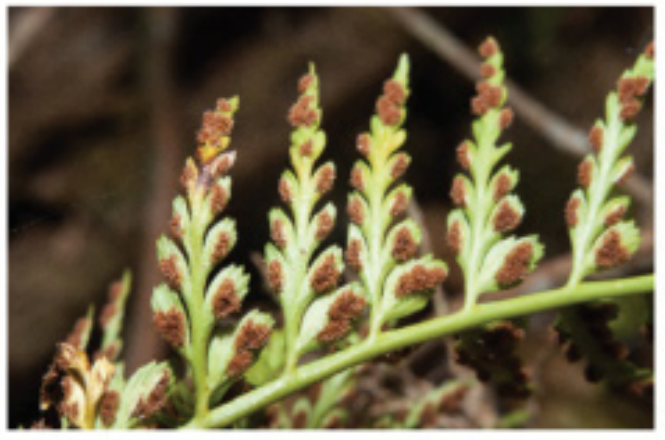

Asplenium auritum

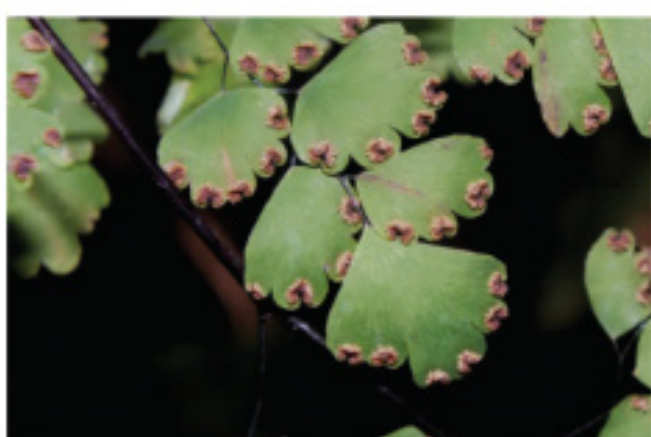

Adiatum raddianum

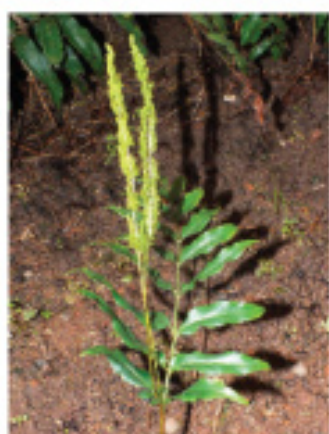

Anemia phyllitidis

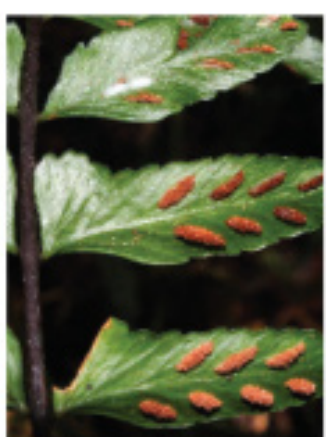

Asplenium auriculatum

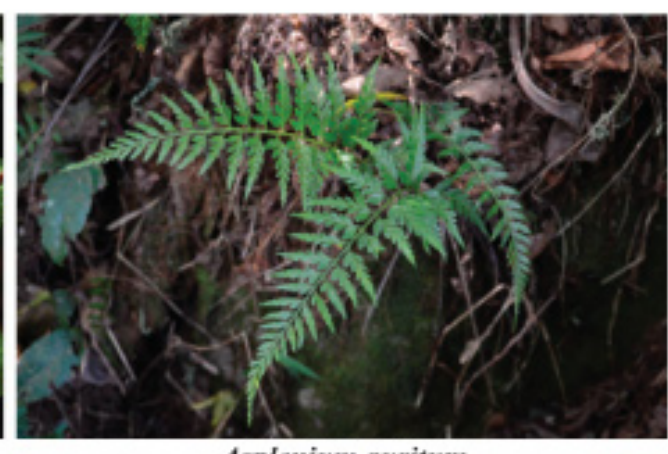

Asplenium auritum

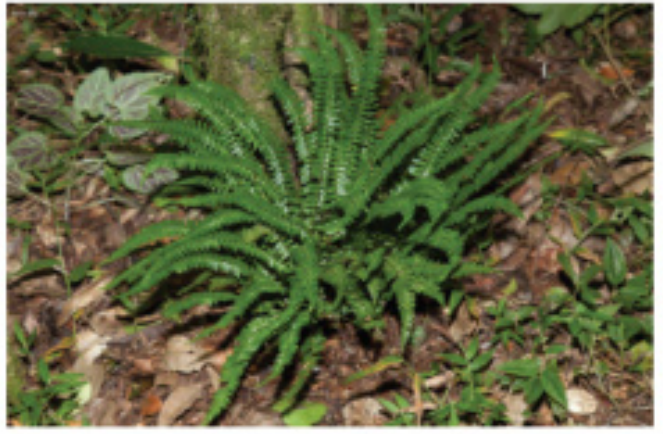

Asplenium claussenii

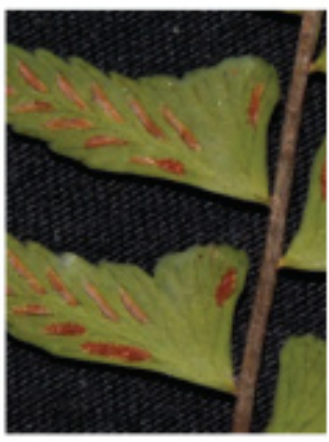

Asplenium claussenii 


\section{Serra da Pedra Branca, Caldas, Minas Gerais, Brasil}

\section{Samambaias e Licófitas da Serra da Pedra Branca}

Eric Arruda Williams, ${ }^{1}$, Massimo Giussepe Bovini² \& Claudine Massi Mynssen

Fundação Jardim Botânico de Poços de Caldas, MG, ${ }^{23}$ Instituto de Pesquisas Jardim Botânico do Rio de Janeiro, RJ.

Fotos: Eric Arruda Williams \& Ederson José de Godoy - Editoração Eletrônica: Elidio Monteiro Junior.

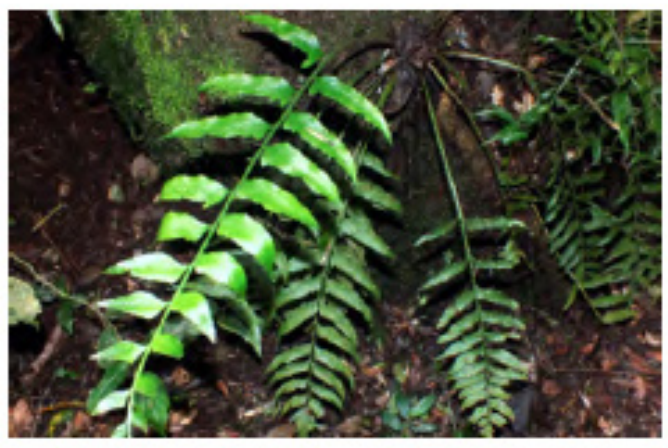

Asplenium feei

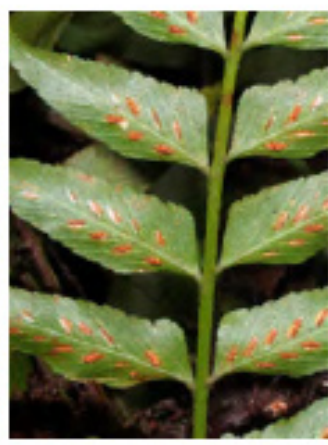

Asplenium feei

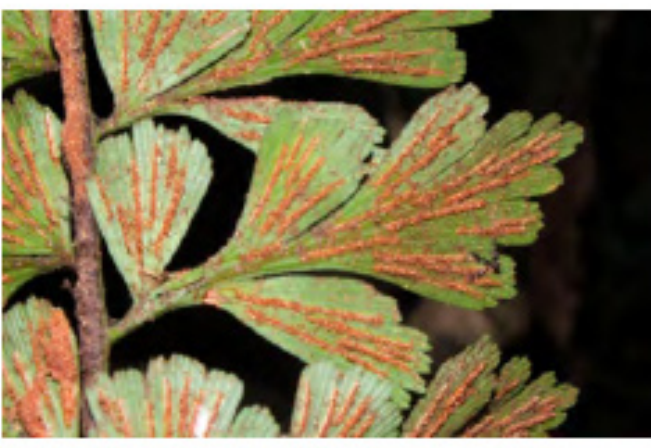

Asplenium praemorsum

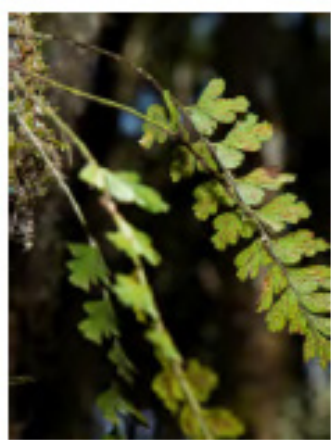

Asplenium praemorsum

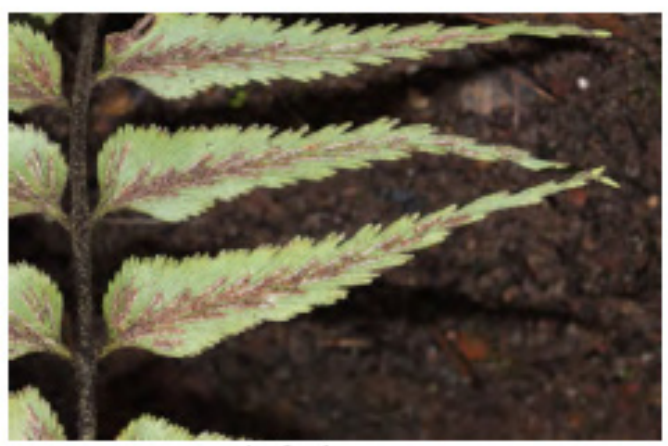

Asplenium serra

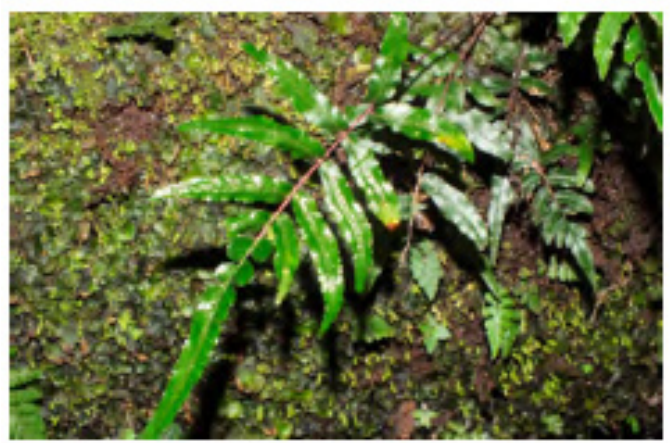

Blechnum gracile

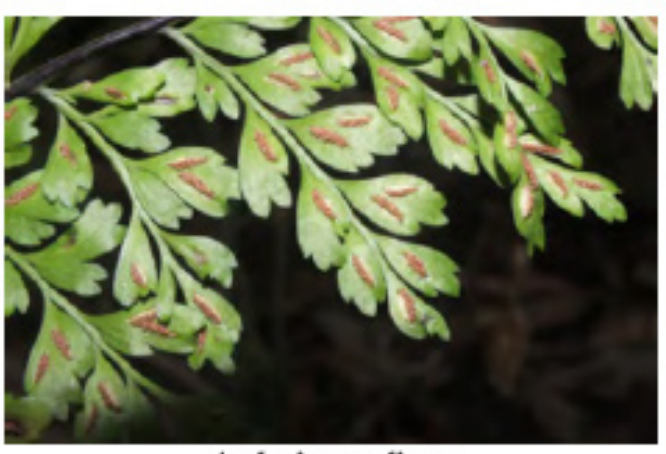

Asplenium radicans

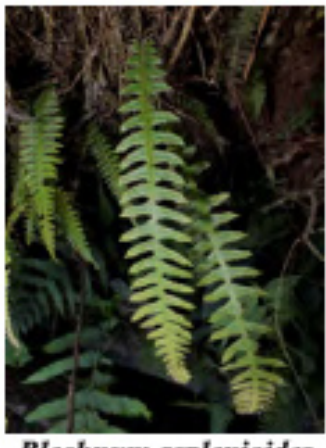

Blechnum asplenioides

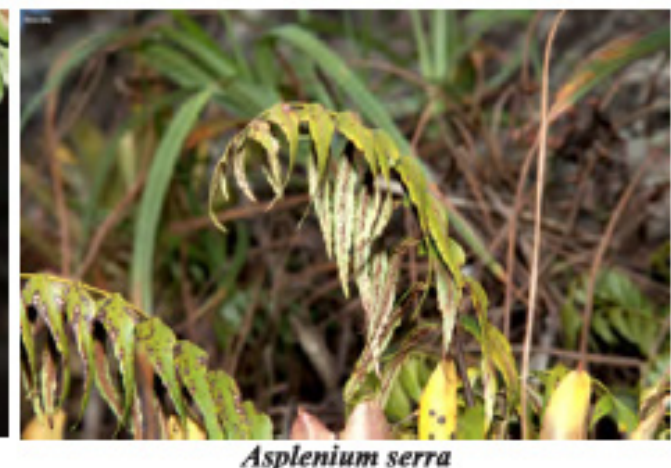

Asplenium serra

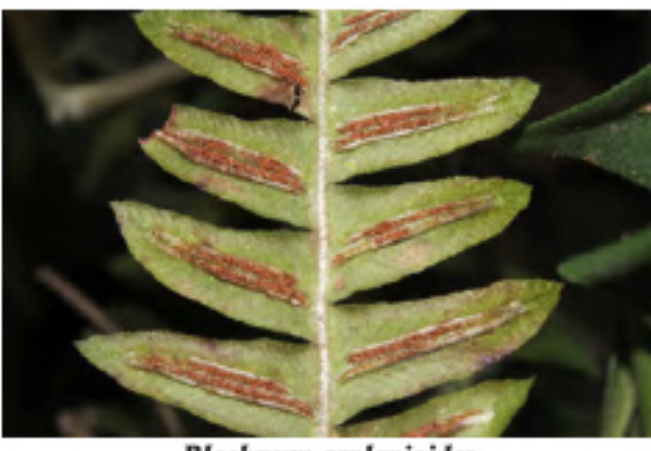

Blechnum asplenioides

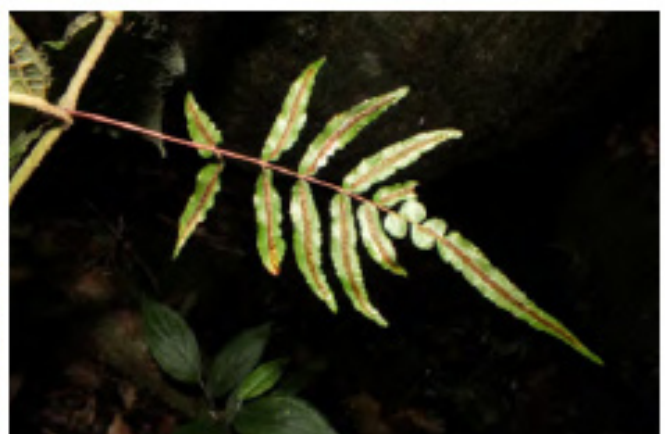

Blechnum gracile

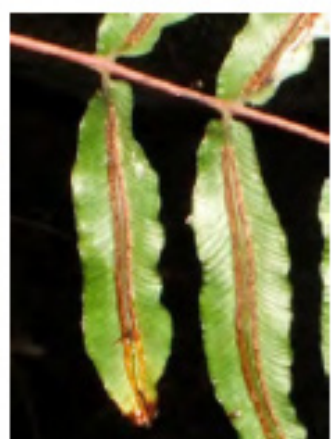

Blechnum gracile 
Serra da Pedra Branca, Caldas, Minas Gerais, Brasil Samambaias e Licófitas da Serra da Pedra Branca

Eric Arruda Williams ${ }^{1}$, Massimo Giussepe Bovini ${ }^{2}$ \& Claudine Massi Mynssen

'Fundação Jardim Botânico de Poços de Caldas, MG, ${ }^{2,3}$ Instituto de Pesquisas Jardim Botânico do Rio de Janeiro, RJ. Fotos: Eric Arruda Williams \& Ederson José de Godoy - Editoração Eletrônica: Elidio Monteiro Junior:

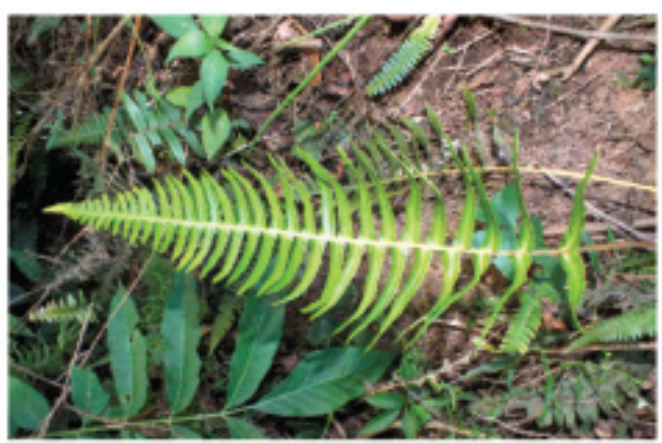

Blechnum occidentale

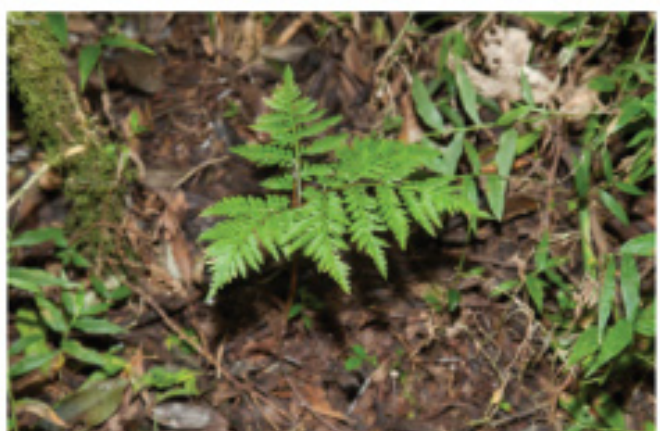

Botrypus virginianus

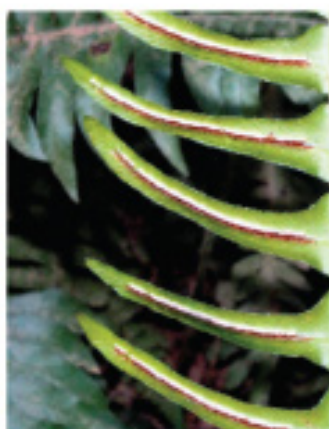

Blechnum occidentale
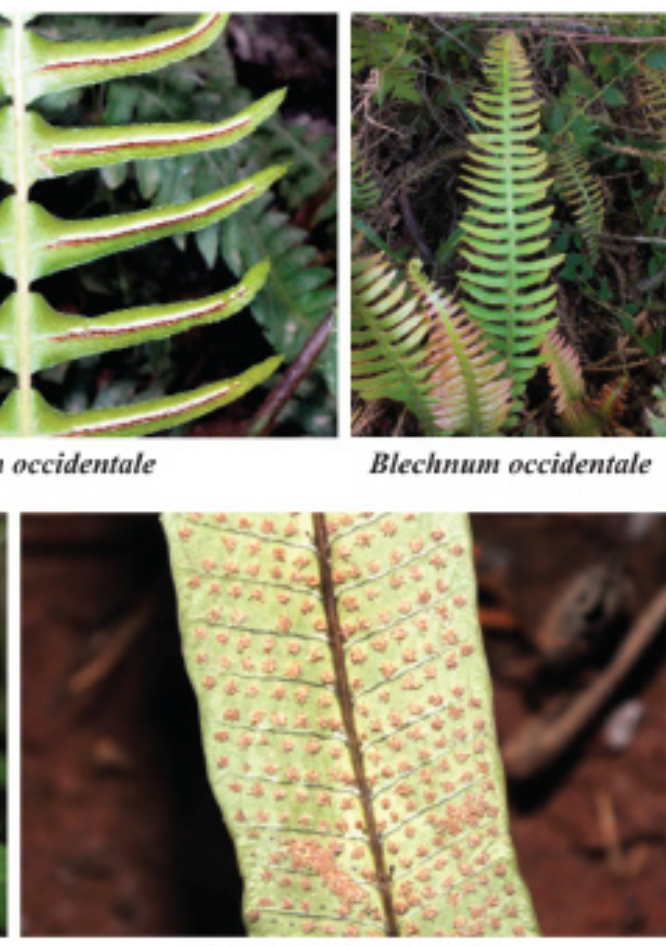

Campyloneurum nitidum

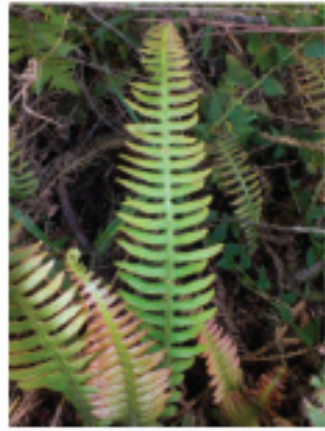

Blechnum occidentale

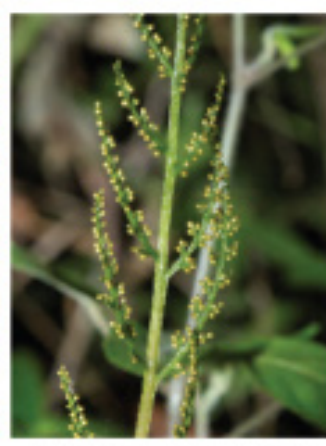

Botrypus virginianus

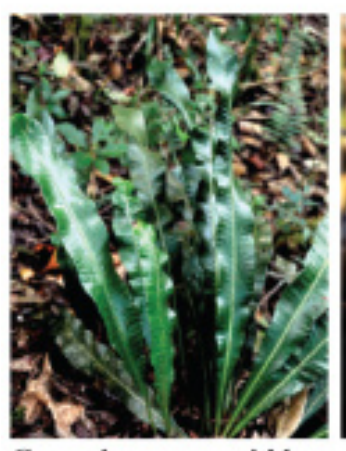

Campyloneurum nitidum

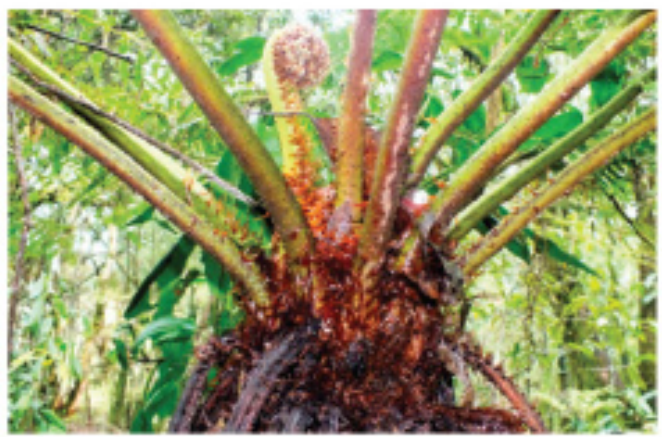

Cyathea delgadii

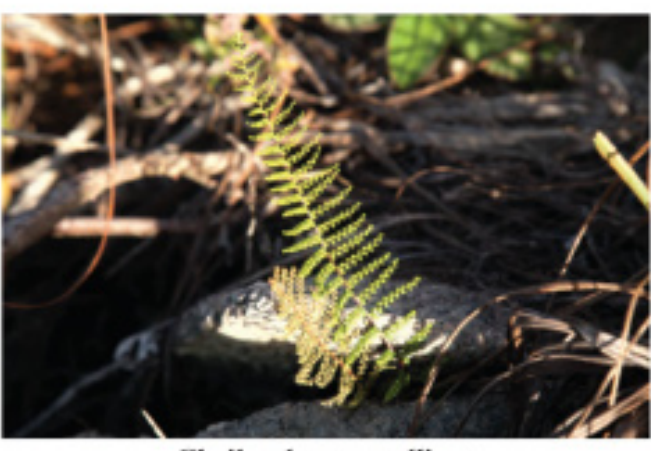

Cheilanthes regnelliana

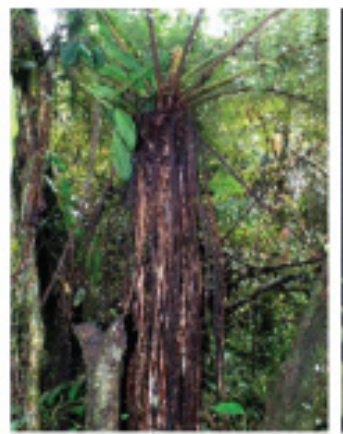

Cyathea delgadii

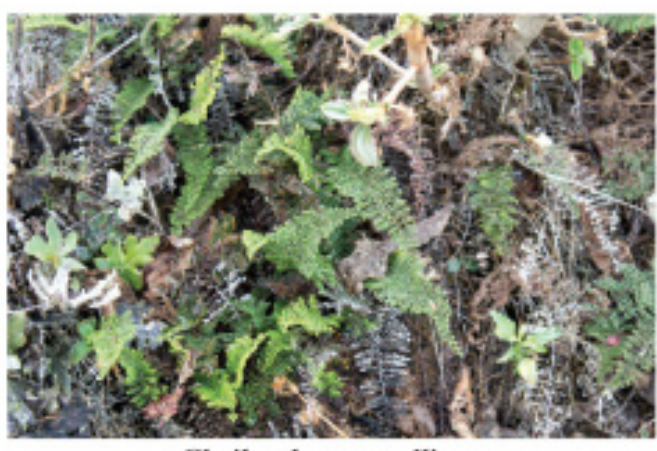

Cheilanthes regnelliana

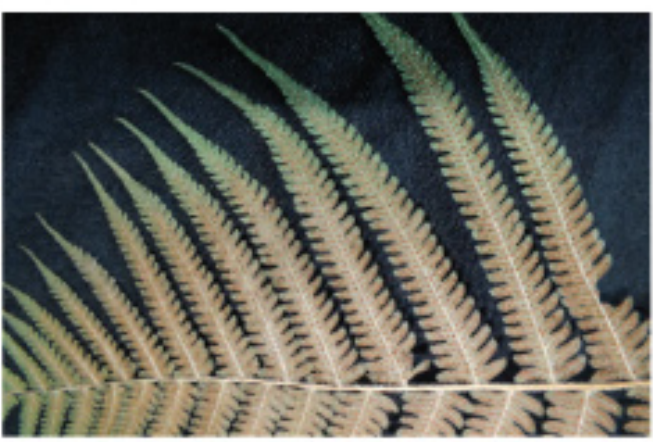

Christella hispidula 
Serra da Pedra Branca, Caldas, Minas Gerais, Brasil

\section{Samambaias e Licófitas da Serra da Pedra Branca}

Eric Arruda Williams', Massimo Giussepe Bovini ${ }^{2}$ \& Claudine Massi Mynssen

'Fundação Jardim Botânico de Poços de Caldas, MG, ${ }^{2.3}$ Instituto de Pesquisas Jardim Botânico do Rio de Janeiro, RJ. Fotos: Eric Arruda Williams \& Ederson José de Godoy - Editoração Eletrônica: Elidio Monteiro Junior.

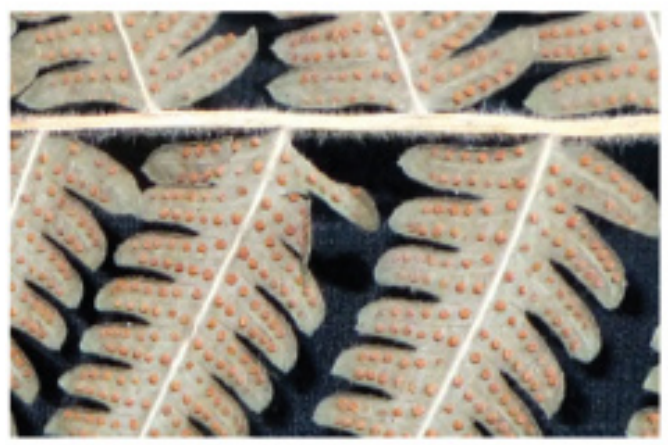

Christella hispidula

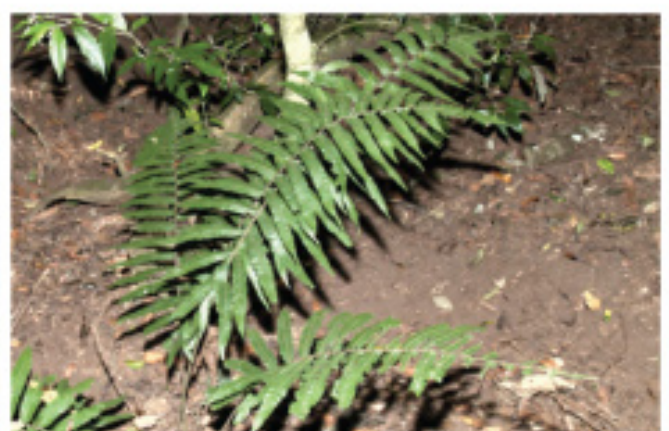

Christella patens

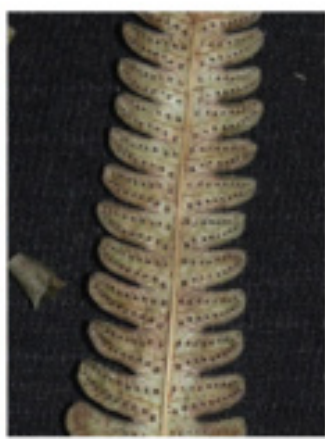

Christella patens

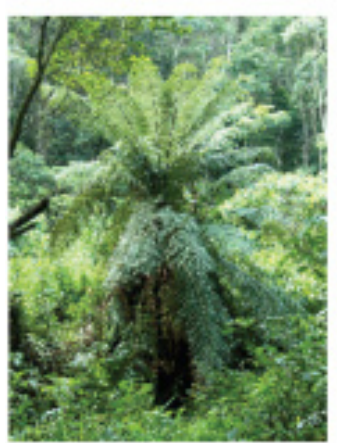

Dicksonia sellowiana

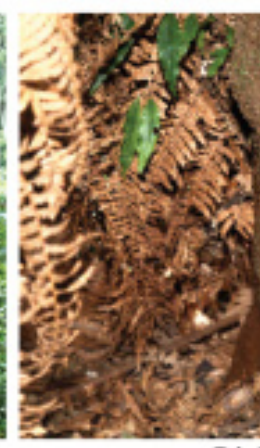

Dicksonia sellowiane

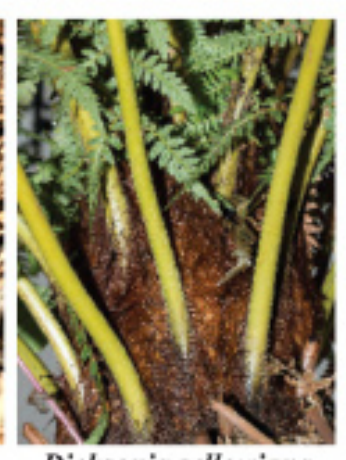

Dicksonia sellowiana

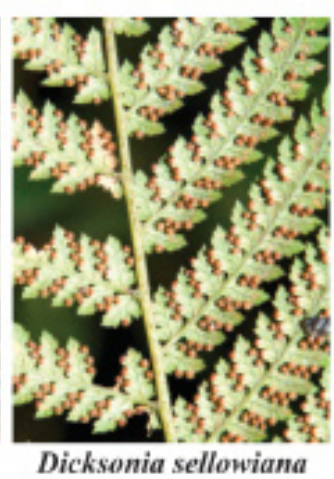

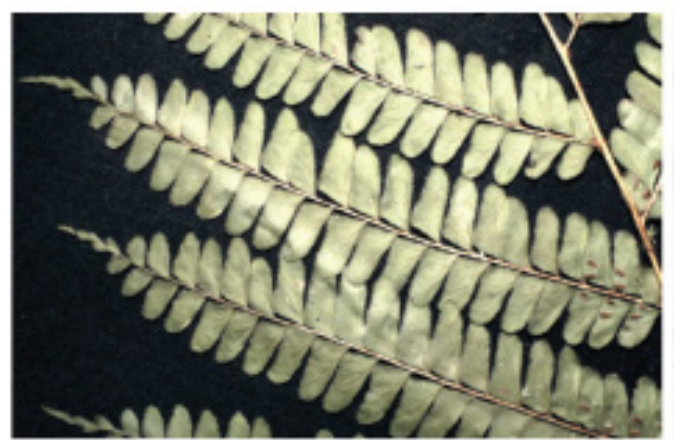

Didymochlaena truncatula

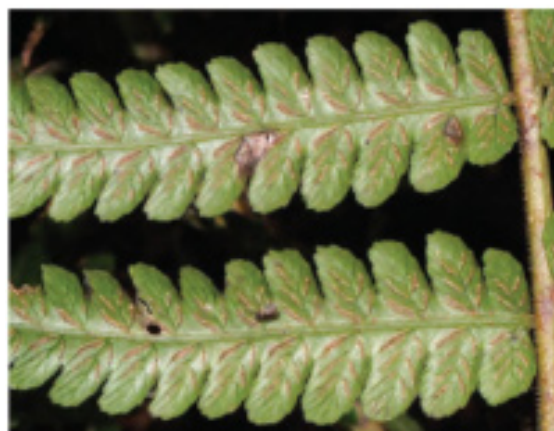

Diplazium asplenioides

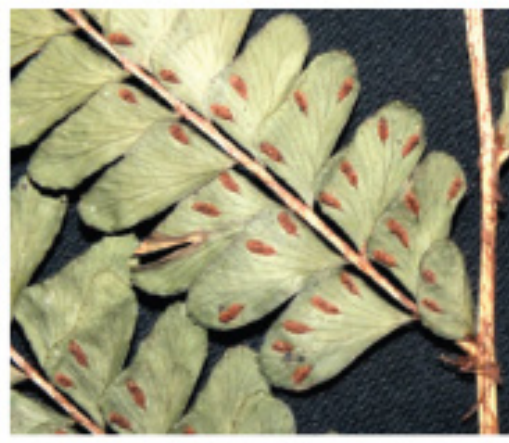

Didymochlaena truncatula

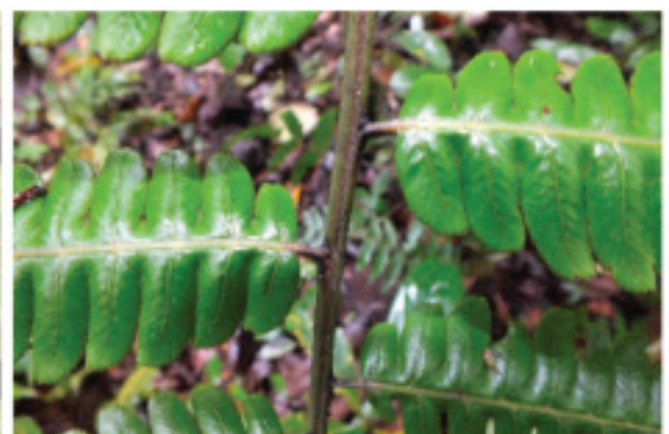

Diplazium lindbergii
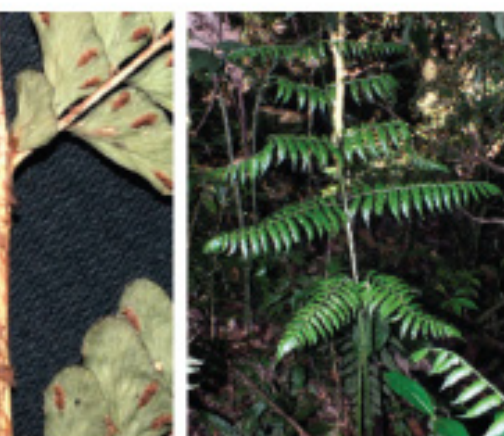

Diplazium asplenioides

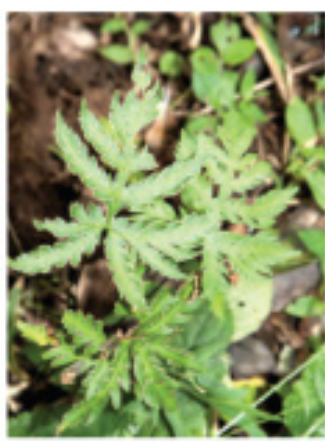

Doryopteris concolor 


\section{Serra da Pedra Branca, Caldas, Minas Gerais, Brasil}

\section{Samambaias e Licófitas da Serra da Pedra Branca}

Eric Arruda Williams ${ }^{3}$, Massimo Giussepe Bovini ${ }^{2}$ \& Claudine Massi Mynssen ${ }^{3}$

${ }^{1}$ Fundação Jardim Botânico de Poços de Caldas, $\mathrm{MG}^{2,3}$ Instituto de Pesquisas Jardim Botânico do Rio de Janeiro, RJ.

Fotos: Eric Arruda Williams \& Ederson José de Godoy - Editoração Eletrônica: Elidio Monteiro Junior.

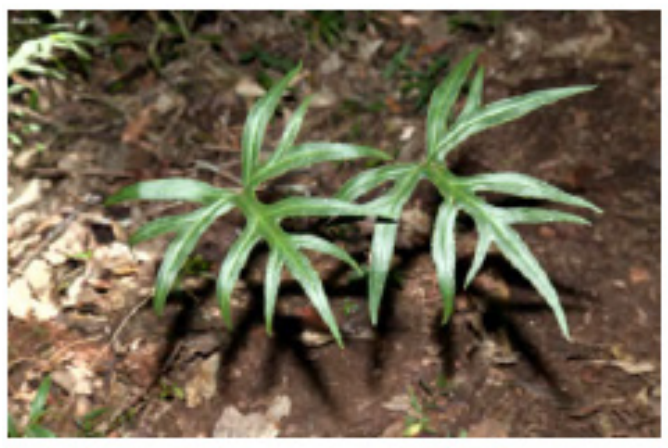

Doryopteris patula

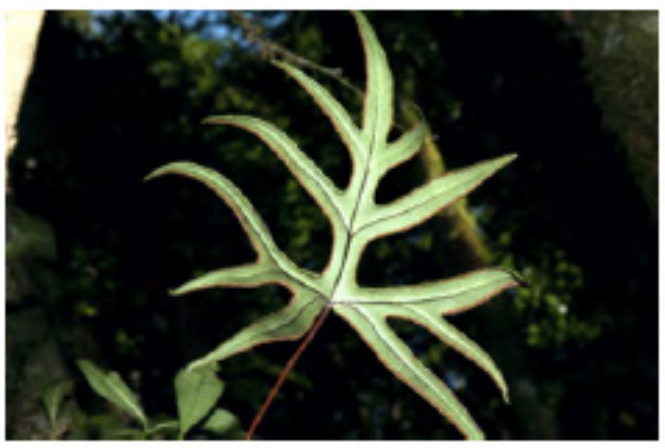

Doryopteris patula

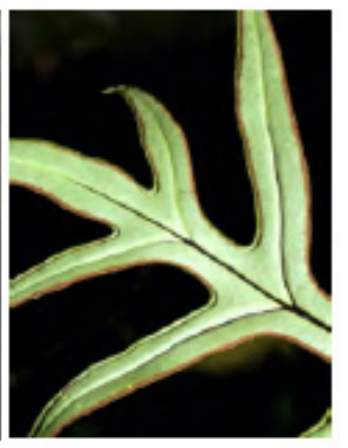

Doryopteris patula

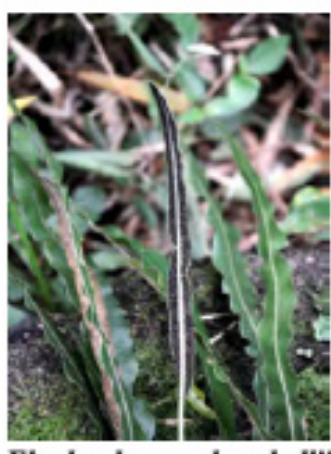

Elaphoglossum burchellit

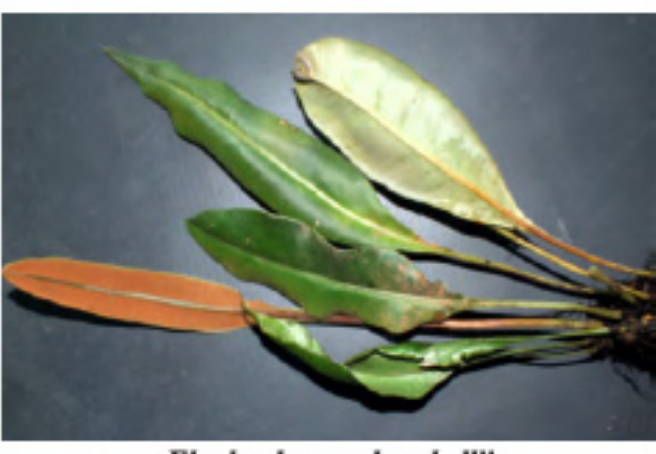

Elaphoglossum burchellii

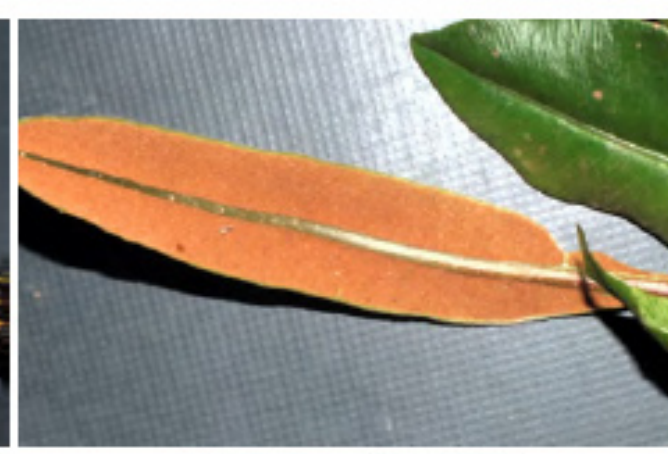

Elaphoglossum burchellii

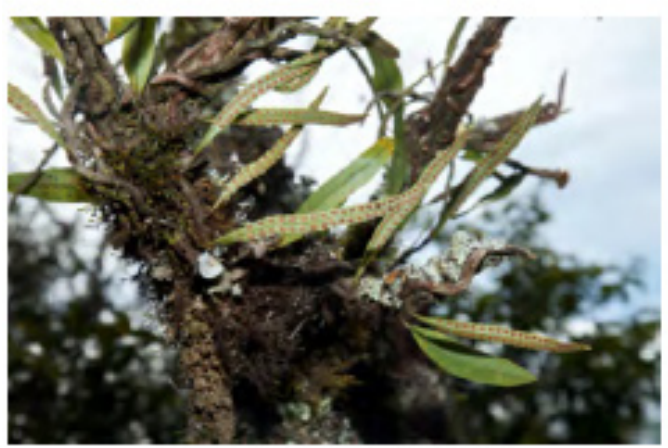

Microgramma squamulosa

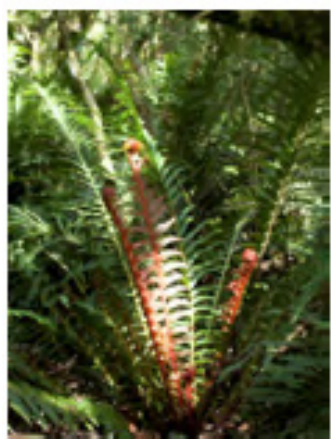

Neoblechnum brasiliense

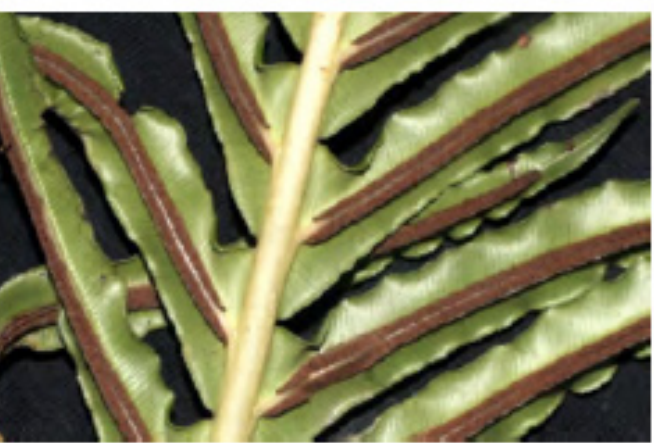

Neoblechnum brasiliense

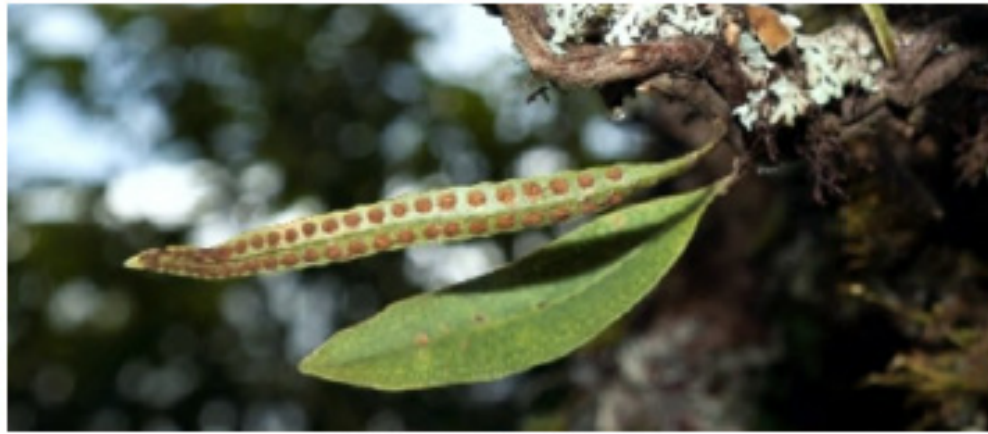

Microgramma squamulosa

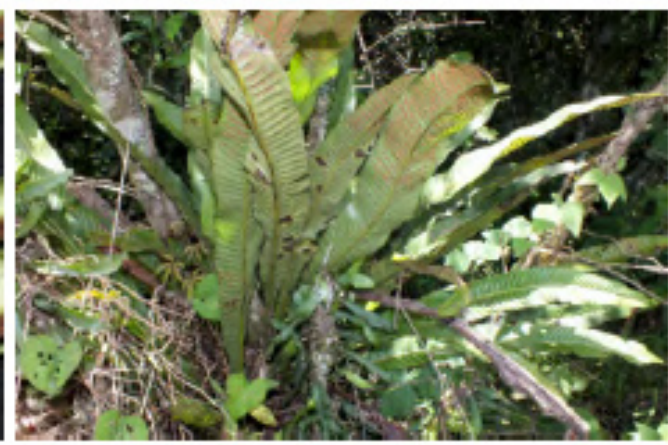

Niphidium crassifolium

\section{5}




\section{Serra da Pedra Branca, Caldas, Minas Gerais, Brasil}

\section{Samambaias e Licófitas da Serra da Pedra Branca}

Eric Arruda Williams ${ }^{1}$, Massimo Giussepe Bovini ${ }^{2} \&$ Claudine Massi Mynssen?

'Fundação Jardim Botânico de Poços de Caldas, MG, ${ }^{23}$ Instituto de Pesquisas Jardim Botânico do Rio de Janeiro, RJ.

Fotos: Eric Arruda Williams \& Ederson José de Godoy - Editoração Eletrônica: Elidio Monteiro Junior.

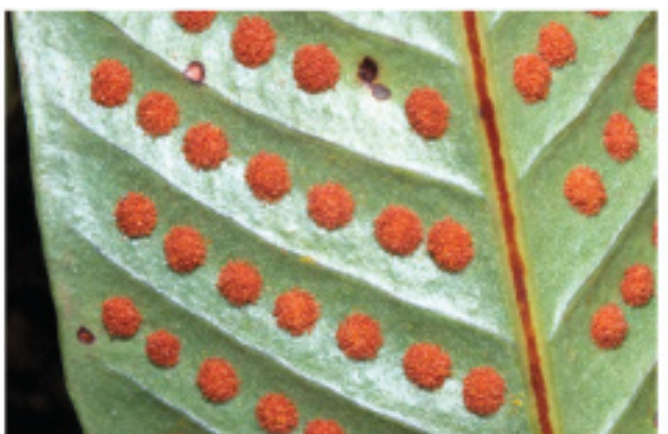

Niphidium crassifolium

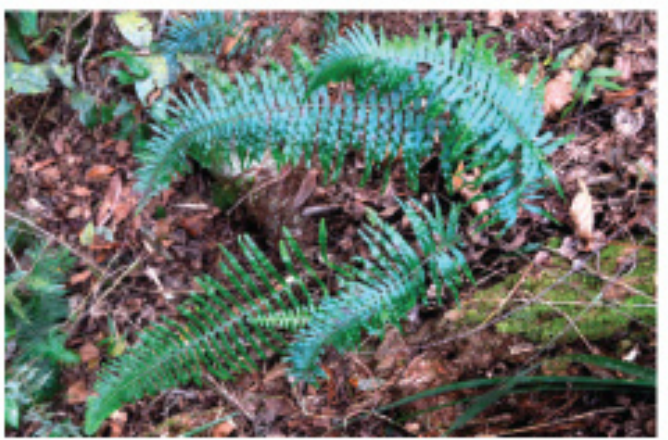

Pecluma robusta

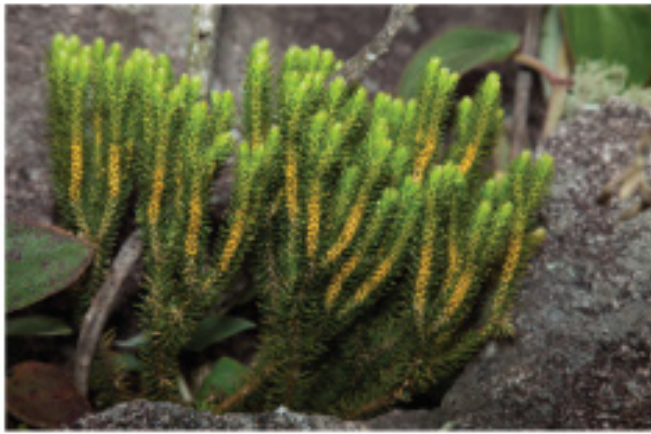

Phlegmariurus regnellii

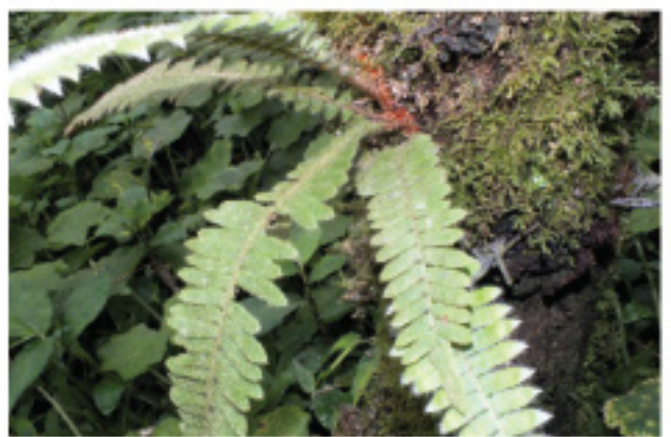

Pleopeltis hisurtissima

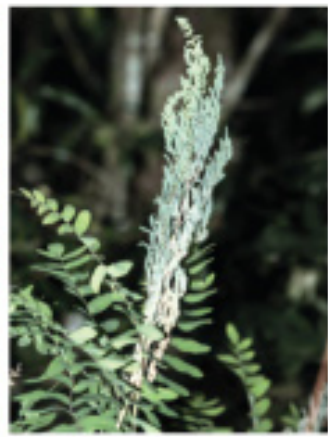

Osmunda spectabilis

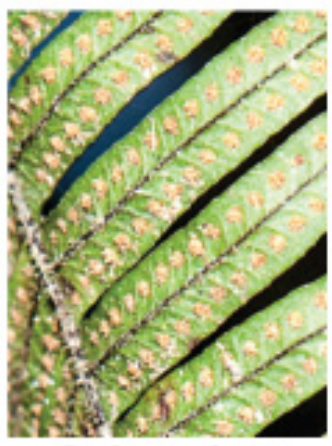

Pecluma robusta

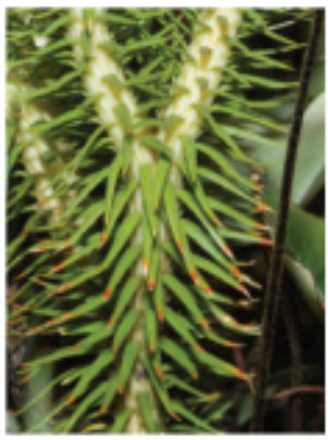

Phlegmariurus regnellii

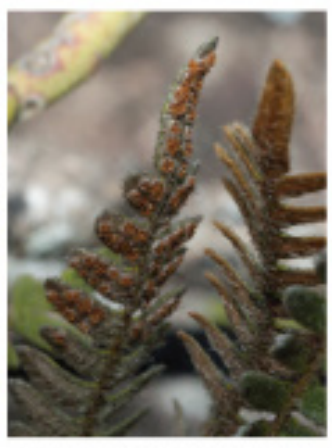

Pleopeltis hisurtissima

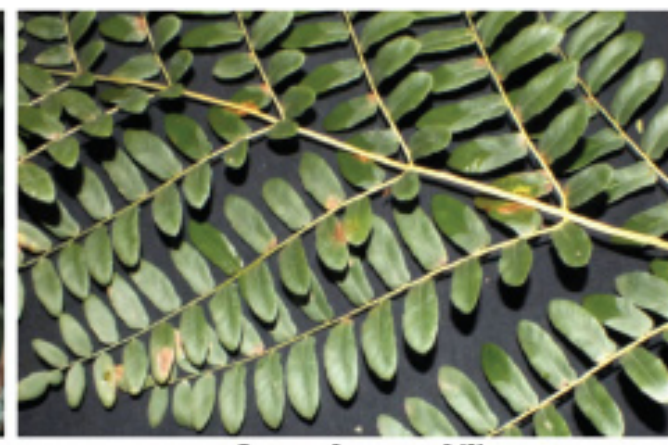

Osmunda spectabilis

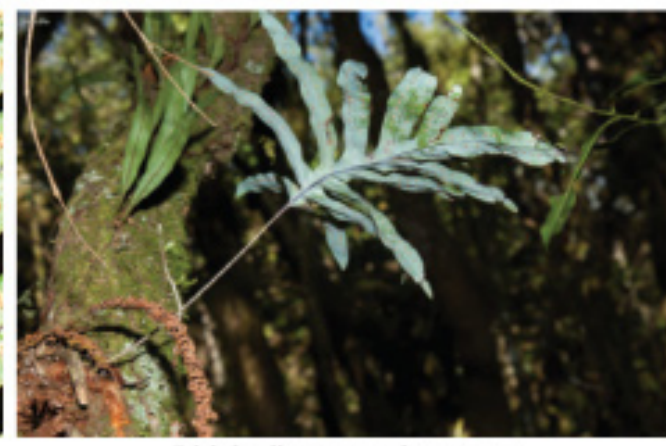

Phlebodium pseudoaureum
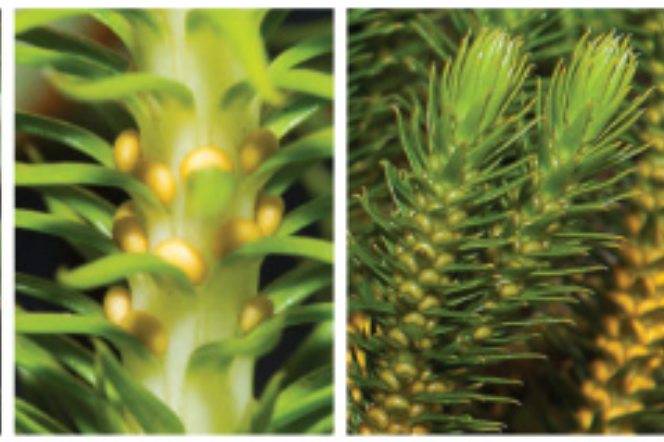

Phlegmariurus regnellii

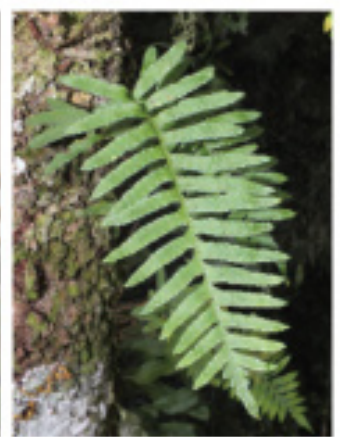

Pleopeltis pleopeltidis

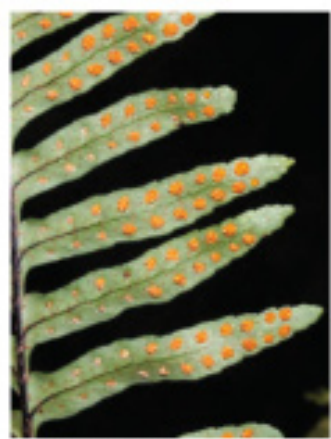

Pleopeltis pleopeltidis 


\section{Serra da Pedra Branca, Caldas, Minas Gerais, Brasil Samambaias e Licófitas da Serra da Pedra Branca}

Eric Arruda Williams ${ }^{1}$, Massimo Giussepe Bovini ${ }^{2}$ \& Claudine Massi Mynssen ${ }^{3}$

${ }^{1}$ Fundação Jardim Botânico de Poços de Caldas, MG, ${ }^{23}$ Instituto de Pesquisas Jardim Botânico do Rio de Janeiro, RJ.

Fotos: Eric Arruda Williams \& Ederson José de Godoy - Editoração Eletrônica: Elidio Monteiro Junior.

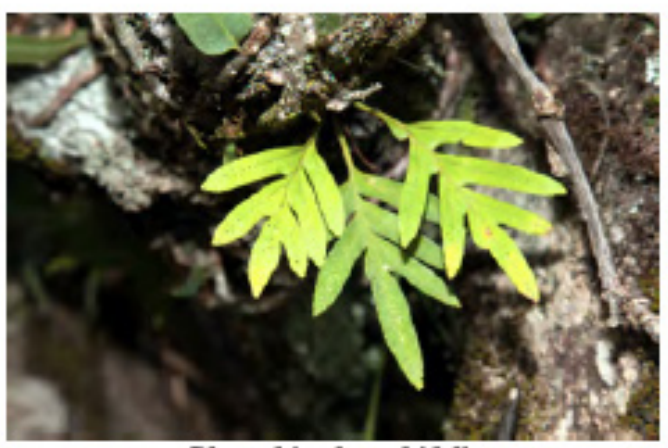

Pleopeltis pleopeltifolia

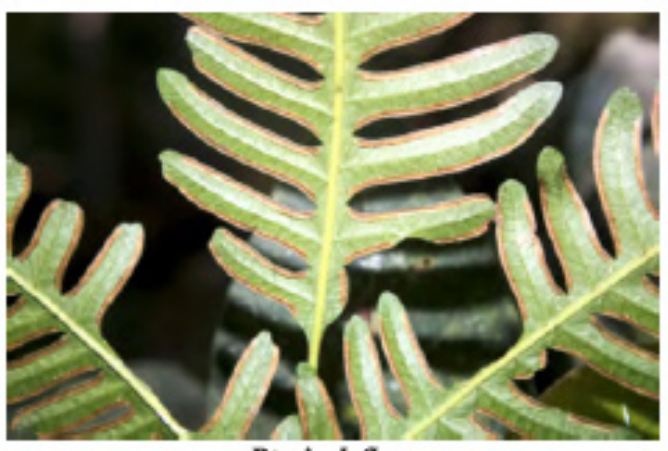

Pteris deflexa

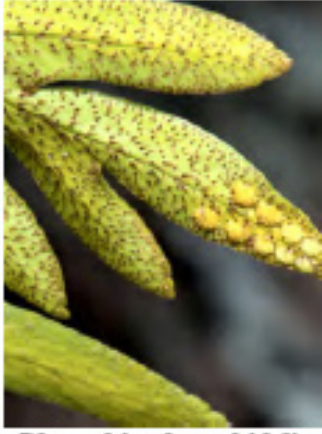

Pleopeltis pleopeltifolia

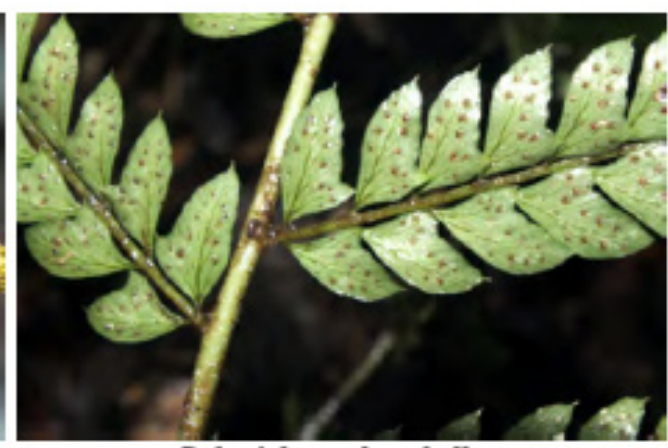

Polystichum platyphyllum

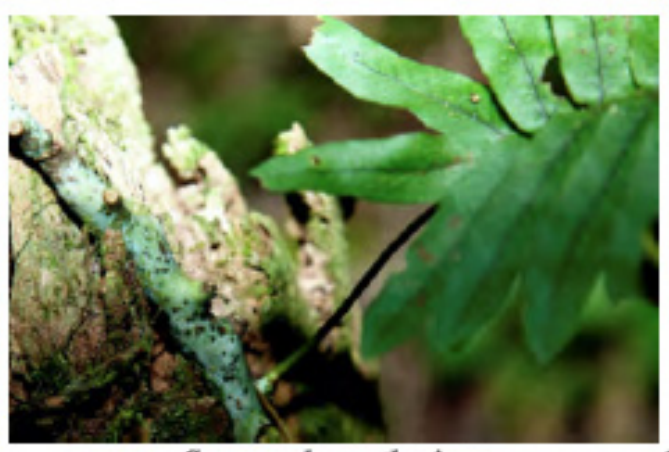

Serpocaulon catharinae

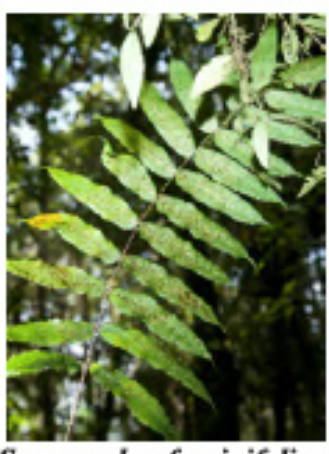

Serpocaulon fraxinifolium 